\title{
Unique Chemistry of Thiuram Polysulfides Enables Energy Dense Lithium Batteries
}

Amruth Bhargav, Ying Ma*, Kollur Shashikala, Yi Cui, Yaroslav Losovyj, and Yongzhu Fu*

A. Bhargav, K. Shashikala, Y. Fu

Department of Mechanical Engineering, Indiana University-Purdue University Indianapolis, Indianapolis, IN 46202, United States

*Corresponding author: yongfu@iupui.edu (Y. Fu)

Y. Cui

Department of Mechanical Engineering, Indiana University-Purdue University Indianapolis, Indianapolis, IN 46202, United States

School of Mechanical Engineering, Purdue University, West Lafayette, IN 47907, United States

Y. Fu

School of Chemistry and Molecular Engineering, Zhengzhou University, Zhengzhou, Henan 450001, China

Y. Losovyj

Department of Chemistry, Indiana University, Bloomington, IN 47405, United States

Y. Ma

Materials Science and Engineering Center, University of Wisconsin-Eau Claire, Eau Claire, WI 54702, United States

*Corresponding author: yingma@uwec.edu (Y. Ma)

KEYWORDS -Thiuram polysulfide, dipentamethylenethiuram tetrasulfide, redox reaction, lithium battery, specific energy

This is the author's manuscript of the article published in final edited form as:

Bhargav, A., Ma, Y., Shashikala, K., Cui, Y., Losovyj, Y., \& Fu, Y. (2017). The unique chemistry of thiuram polysulfides enables energy dense lithium batteries. Journal of Materials Chemistry A, 5(47), 25005-25013. https://doi.org/10.1039/C7TA07460C 


\begin{abstract}
Organosulfur compounds are cheap and abundant cathode materials that can offer high specific energies. Herein, we explore for the first time, the common vulcanization accelerators viz. thiuram polysulfides embedded in carbon nanotubes as binder-free cathodes in lithium batteries that show 3 highly reversible redox reactions (3 discharge plateaus) and high material utilization (up to 97\%). We use electrochemical characterization techniques, first-principles calculations, XPS, XRD, FTIR, and SEM to gain insight into the chemical transformations occurring during battery cycling. We identify that the mesomeric form of lithium pentamethylene dithiocarbamate with a positive nitrogen center, formed in the discharge, can act as polysulfide and sulfide anchors through strong Coulombic interactions thus enabling a capacity retention of $87 \%$ after 100 cycles at C/5 rate. High loading cathode with an areal capacity of $5.3 \mathrm{mAh} \mathrm{cm}^{-2}$ tested under a low electrolyte to active material ratio of $3 \mu \mathrm{L} \mathrm{mg}{ }^{-1}$ yields an active material specific energy of $1,156 \mathrm{Wh} \mathrm{kg}^{-1}$ thus demonstrating the potential of this class of compounds in high specific energy lithium batteries.
\end{abstract}

\title{
Introduction
}

Lithium-ion batteries have been instrumental in bringing about the age of portable personal electronics and electric cars over the past two decades. ${ }^{1,2}$ This growth has increased the demand for high energy density batteries to power them. High energy density battery chemistries such as $\mathrm{Li}-\mathrm{S}$ and $\mathrm{Li}-\mathrm{O}_{2}$ seem promising in meeting this demand. ${ }^{3-5} \mathrm{Li}-\mathrm{S}$ chemistry is facing some key technical challenges preventing it from widespread use. The predominating one being the polysulfide shuttle effect due to the soluble lithium polysulfides $\left(\mathrm{Li}_{2} \mathrm{~S}_{6-8}\right)$ when utilizing ethereal electrolytes leading to low Coulombic efficiency and loss of active material. Improvements in material design over the years such as utilizing tailored carbonaceous ${ }^{6,7}$ and non-carbonaceous ${ }^{8,9}$ 
materials have helped alleviate this issue to an extent. Despite this, sulfur electrodes with high sulfur loading suffer from low material utilization. ${ }^{10-12}$ Furthermore, a high electrolyte-sulfur ratio (>10 $\mu \mathrm{L} \mathrm{mg}^{-1}$ ) enables good performance but lowers the energy density thus negating the promise of Li-S chemistry. ${ }^{13,14}$ Conversely, low electrolyte-sulfur ratio $\left(<5 \mu \mathrm{L} \mathrm{mg}^{-1}\right)$ increases energy density while lowering cycling performance. ${ }^{15}{ }^{16}$ However, the ability to tune the electrochemistry through the use of organosulfur compounds as active materials can circumvent some of these issues. Recent works clearly highlight this potential of organosulfur compounds. ${ }^{17}$, 18

Organosulfur compounds, thus, can offer high specific energy as high as $1,700 \mathrm{Wh} \mathrm{kg}^{-1}$ making them alternate candidates for high specific energy lithium batteries. ${ }^{17,19,20}$ Pioneering work on this class of compounds was done by Visco and others. ${ }^{19-23}$ In their early works, they identified the potential of using thiuram disulfides as active materials in lithium batteries. However, the practical potential of these thiuram disulfides is limited owing to their low specific capacities. Despite the promising performance, higher order thiuram polysulfides have not been explored to the best of our knowledge.

Thiuram polysulfides such as dipentamethylene thiuram tetrasulfide (PMTT) and dipentamethylenethiuram hexasulfide (PMTH) are commercially available and are commonly used as vulcanization accelerators in the rubber industry. ${ }^{24}$ This makes them easily available and cost-effective materials for battery application. Herein, we explore the utilization of PMTT or PMTH as a composite in carbon nanotubes (CNT) as a cathode material. Appealing electrochemical performance supported by theoretical calculations, in-depth spectroscopic and microscopic analysis of the discharge-charge process is presented. The usability of these materials with practical level of loading is also explored. 


\section{Experimental}

\section{Materials:}

Dipentamethylenethiuram tetrasulfide (PMTT, $\mathrm{C}_{12} \mathrm{H}_{20} \mathrm{~N}_{2} \mathrm{~S}_{6}, \mathrm{MP}$ Biomedicals), dipentamethylenethiuram hexasulfide (PMTH, $\mathrm{C}_{12} \mathrm{H}_{20} \mathrm{~N}_{2} \mathrm{~S}_{8}, 95 \%$, Pfaltz \& Bauer), carbon nanotubes (CNT, 95\%, OD: 10-20 nm, L: 30-100 $\mu \mathrm{m}$, Nanostructure and Amorphous Materials, Inc.), ethanol ( $\mathrm{C}_{2} \mathrm{H}_{5} \mathrm{OH}$, Fisher Chemical), lithium bis(trifluoromethanesulfonimide) (LiTFSI, $\mathrm{LiN}\left(\mathrm{CF}_{3} \mathrm{SO}_{2}\right)_{2}$, 99\%, Acros Organics), lithium nitrate ( $\mathrm{LiNO}_{3}, 99.999 \%$, Acros Organics), 1,2dimethoxyethane (DME, 99.5\%, Sigma Aldrich), 1,3-dioxolane (DOL, 99.8\%, Sigma Aldrich), dimethyl sulfoxide-d 6 (99.9 atom \% D, Sigma Aldrich), carbon disulfide (CS 2 , anhydrous, $\geq 99 \%$, Sigma Aldrich), and potassium bromide (KBr, FTIR Grade, Alfa Aesar) were purchased and used as received.

\section{PMTT/PMTH cathode fabrication:}

PMTT or PMTH and CNT were taken in 2:1 wt. ratio (typically $250 \mathrm{mg}$ of PMTT/PMTH with $125 \mathrm{mg} \mathrm{CNT}$ ) and stirred in $300 \mathrm{~mL}$ of ethanol for 15 minutes to disperse them. This mixture was later ultrasonicated using a vibracell VC505 sonicator for 15 minutes to entrap the polysulfide particles in interwoven CNT. Following this, the mixture was vacuum filtered on a 7cm membrane. The resulting composite paper was easily peeled off the membrane and dried under vacuum at $50^{\circ} \mathrm{C}$ overnight to yield the cathode paper. The PMTT/PMTH as obtained from the manufacturer has $\leq 5 \%$ as oil content. This oil was dissolved in ethanol during dispersion which was verified by the absence of $~ 3 \%$ residue in TGA. This results in cleaner PMTT/PMTH deposited on the cathode. 


\section{Lithium polysulfide cathode fabrication:}

Lithium polysulfide solution in ethanol was prepared by adding stoichiometric amounts of sulfur powder and $\mathrm{Li}_{2} \mathrm{~S}$ and stirring overnight to give a $0.5 \mathrm{M} \mathrm{Li}_{2} \mathrm{~S}_{6}$ (3 $\mathrm{M}$ sulfur) solution. Then, $20 \mu \mathrm{L} \mathrm{Li}_{2} \mathrm{~S}_{6}$ solution was added into a CNT paper current collector $\left(0.97 \mathrm{~cm}^{2}\right.$ in area, $4-4.2$ mg in mass, prepared as reported previously ${ }^{17}$ ) and dried in the glove box. Afterwards, another $16 \mu \mathrm{L}$ of $\mathrm{Li}_{2} \mathrm{~S}_{6}$ was added, and the $\mathrm{Li}_{2} \mathrm{~S}_{6} / \mathrm{CNT}$ was dried again. The corresponding sulfur mass in the electrode is $3.46 \mathrm{mg}\left(3.57 \mathrm{mg} \mathrm{cm}^{-2}\right)$ which equates to an areal capacity of $\sim 6 \mathrm{mAh} \mathrm{cm}^{-2}$.

\section{Cell fabrication and electrochemical evaluation:}

7/16 inch discs were punched from the PMTT-CNT and PMTH-CNT composite paper to be used as cathodes. The active material loading was determined by weighing the cathodes and noting the active material fraction from thermogravimetric analysis (TGA). PMTT cathodes had an active material loading of 6-8 $\mathrm{mg} \mathrm{cm}^{-2}$ and that of PMTH was 5-7 $\mathrm{mg} \mathrm{cm}^{-2}$. The electrolyte was composed of 1.0 M LiTFSI and 0.2 $\mathrm{M} \mathrm{LiNO}_{3}$ in mixture solvent of DME and DOL (1:1 v/v). CR2032 type coin cells were fabricated inside the glove box. For the normal cells, electrolyte was added to the cathode disc. Celgard 2400 separator was placed on the cathode. Following which, $20 \mu \mathrm{L}$ electrolyte was added on top of the separator. Finally, lithium metal anode was placed on the separator. The cell was crimped and taken out of the glove box for testing. The amount of electrolyte on the cathode side was adjusted to have a nominal electrolyte to active material ratio of $6 \mu \mathrm{L} \mathrm{mg}{ }^{-1}$. High loading cells utilized two cathode discs and $10 \mu \mathrm{L}$ electrolyte on the anode side while adjusting the electrolyte on the cathode side to maintain a low electrolyte to active material ratio of $3 \mu \mathrm{L} \mathrm{mg}^{-1}$. Cells with $\mathrm{Li}_{2} \mathrm{~S}_{6} / \mathrm{CNT}$ cathodes were made using the same procedure while adding electrolyte to achieve electrolyte to sulfur ratio of $5 \mu \mathrm{L} \mathrm{mg}^{-1}$ and $10 \mu \mathrm{L} \mathrm{mg}^{-1}$. 
Cyclic voltammetry (CV) was performed on a BioLogic VSP potentiostat. The potential was swept from open circuit voltage (OCV) to $1.8 \mathrm{~V}$ and then swept back to $3.0 \mathrm{~V}$ at a scanning rate of $0.05 \mathrm{mV} \mathrm{s}^{-1}$. Cells were galvanostatically cycled between 1.8 and $3.0 \mathrm{~V}$ on an Arbin BT2000 battery cycler at different $\mathrm{C}$ rates $\left(1 \mathrm{C}=417 \mathrm{~mA} \mathrm{~g}^{-1}\right.$ for PMTT and $598 \mathrm{~mA} \mathrm{~g}^{-1}$ for PMTH based on the mass of active material in the cells).

\section{Computations:}

Geometry optimization and total energy calculations based on the density functional theory (DFT) were performed using SPARTAN software package (Wave function, Irvine, CA).

The M06-2X exchange-correlation functional and the 6-31G* basis set were used. ${ }^{25}$ To simulate the effect of the solvent, a polarizable continuum model (PCM) was used, and the dielectric constant was set to that of DME that was used as electrolyte in this study (the dielectric constant of DOL is similar to that of DME)

\section{Materials characterization:}

The PMTT or PMTH content in the composite paper was determined by TGA performed on a TA instruments SDT Q600 analyzer under argon flow at $50 \mathrm{~mL} \mathrm{~min}^{-1}$ while heating from $25^{\circ} \mathrm{C}$ to $500^{\circ} \mathrm{C}$ at $10^{\circ} \mathrm{C} \mathrm{min}^{-1}$. Samples of CNT were run as a baseline.

Cells used for materials characterization was cycled using a $0.5 \mathrm{M} \mathrm{LiNO}_{3}$ in DME/DOL $(1: 1 \mathrm{v} / \mathrm{v})$ electrolyte (to avoid presence of sulfur from it) at C/20 till the appropriate cut-off voltage. The cell was then opened, the cathode was extracted, washed using DME and dried in glovebox atmosphere before mounting on instrument sample holders. The samples were transferred to the instrument in an argon-filled airtight container.

X-ray photoelectron spectroscopy (XPS) experiments were performed using PHI Versa Probe II instrument equipped with focused monochromatic $\mathrm{Al} \mathrm{K \alpha}$ source. The X-ray power of 50 
$\mathrm{W}$ at $15 \mathrm{kV}$ was used for $200 \mu \mathrm{m}$ beam size. The PHI dual charge compensation system was used on all samples. XPS spectra with the energy step of $0.1 \mathrm{eV}$ were recorded using software SmartSoft-XPS v2.0 and processed using Casa 2.317 software. The spectrum was calibrated using HOPG strips attached alongside the samples as standard and setting its $\mathrm{C}$ 1s binding energy (BE) to $284.4 \mathrm{eV}$ and verified using adventitious (aliphatic) carbon BE. ${ }^{26}$ The XPS spectra were fitted using a combination of Gaussians and Lorentzians with 0-50\% of Lorentzian contents. Shirley background was used for curve-fitting. The $S 2 \mathrm{p}_{3 / 2}$ and $\mathrm{S} 2 \mathrm{p}_{1 / 2}$ doublets were constrained using peak areas of 2:1 with a splitting of $1.18 \mathrm{eV}$.

X-ray diffraction (XRD) data were collected on a Bruker D8 Discover XRD Instrument equipped with $\mathrm{Cu} \mathrm{K} \alpha$ radiation. The samples were protected in the sample holder with Kapton film. The scanning rate was $2^{\circ} \min ^{-1}$, for $2 \theta$ between $20^{\circ}$ and $60^{\circ}$.

Fourier transform infrared (FTIR) absorption spectra were recorded on a Thermo Scientific-Nicolet iS10 FTIR spectrometer. 32 scans between $400 \mathrm{~cm}^{-1}$ to $4000 \mathrm{~cm}^{-1}$ were recorded per sample. Samples were prepared by grinding the cathodes with $\mathrm{KBr}$ within the glovebox and pelletizing it using an FTIR die set.

${ }^{1} \mathrm{H}$-Nuclear magnetic resonance (NMR) was carried out on a Bruker Avance III $400 \mathrm{MHz}$ NMR spectrometer. The cathode was soaked in $1 \mathrm{~mL}$ of DMSO-D 6 :CS $2(1: 1 \mathrm{v} / \mathrm{v})$ solution overnight to extract the active material. $700 \mu \mathrm{L}$ of the supernatant liquid was subject to NMR analysis and the chemical shifts $(\delta)$ are referenced downfield from tetramethylsilane ((CH3) $\left.{ }_{4} \mathrm{Si}\right)$ using the residual solvent peak as an internal standard.

Scanning electron microscopy (SEM) of the electrodes was performed using a JEOL JSM-7800F microscope. The elemental mapping was performed with energy-dispersive X-ray 
spectroscopy (EDX) attached to the SEM at $10 \mathrm{kV}$ to confirm the presence of sulfur in particles of electrodes.

\section{Results and Discussion}

PMTT is first in our study followed by PMTH as both show similar electrochemical behavior. Commercial PMTT appears as a buff-colored powder which is stable in air, as shown in Figure 1a along with its chemical structure. PMTT has a theoretical specific capacity of 418 $\mathrm{mAh} \mathrm{g}{ }^{-1}$ considering a $6 \mathrm{e}^{-}$reduction reaction. The 4 single-bonded sulfur atoms are the active sites. The middle 2 sulfur atoms could take $2 \mathrm{e}^{-}$each to form 2 lithium sulfides $\left(\mathrm{Li}_{2} \mathrm{~S}\right)$, while the other 2 sulfur atoms could take $1 \mathrm{e}^{-}$each to yield 2 lithium pentamethylene dithiocarbamates (LiPMDTC, $\left.\mathrm{C}_{5} \mathrm{H}_{10} \mathrm{NCSSLi}\right) .{ }^{21}$ The PMTT-CNT composite cathode prepared by the dispersionthen-filtration method is free-standing and free of binders and could be used as cathode without additional current collectors. This provides a simple, efficient and scalable process for cathode preparation. Thermogravimetric analysis (TGA) as seen in Figure S1 (ESI) shows that PMTT constitutes $67 \%$ of the cathode weight demonstrating that all the PMTT is extracted during the filtration process.

The electrochemical behavior of the PMTT cathode was first evaluated in lithium half cells. Cyclic voltammetry (CV) performed at $0.05 \mathrm{mV} \mathrm{s}^{-1}$ shows the redox characteristics of PMTT (Figure 1b). In the cathodic scan from open circuit voltage (OCV) to $1.8 \mathrm{~V}$, we encounter the first reduction peak at $2.57 \mathrm{~V}$ (marked as I) which could be due to the formation of LiPMDTCs. ${ }^{23}$ Further reduction of the intermediates occurs at $2.34 \mathrm{~V}$ (II) and $2.05 \mathrm{~V}$ (III) leading to complete conversion by $1.8 \mathrm{~V}$. This process is reversed in the anodic scan with IV and V following conversions at III and II respectively followed by the addition of the dithiocarbamate group at 2.67 V (VI) to yield PMTT. The continuous overlap of these peaks 
over 10 cycles confirms the good electrochemical reversibility of the redox processes. The CV of PMTT highlights a departure from the typical profile for Li-S batteries (Figure S2, ESI) due to the addition of the high voltage processes of I and VI. ${ }^{7}$ This leads to a higher average cell voltage thus potentially increasing the cell specific energy and energy density when using thiuram polysulfides as cathode materials in lithium batteries.

On examining the voltage profile for a cell galvanostatically cycled at $\mathrm{C} / 5$ shown in Figure 1c we can see that from an OCV of $2.96 \mathrm{~V}$ the first plateau occurs at $2.53 \mathrm{~V}$ followed by further reduction plateaus at $2.33 \mathrm{~V}$ and $2.1 \mathrm{~V}$. The following charge has a sloping plateau (IV) followed by two more oxidation steps. It is very evident that processes (I-VI) during cycling occur with little overpotential from those of the CV. The corresponding cycling performance of this cell shown in Figure 1d shows a high first discharge specific capacity of $406 \mathrm{mAh} \mathrm{g}^{-1}$ which corresponds to $97 \%$ of the theoretical capacity i.e. an almost complete $6 \mathrm{e}^{-}$transfer to PMTT while maintaining a Coulombic efficiency (CE) of 99.93\%. These results demonstrate excellent material utilization and reversibility of this material despite the high active material loading of $6.7 \mathrm{mg} \mathrm{cm}^{-2}$ while operating at moderate electrolyte to PMTT ratio of $\sim 6 \mu \mathrm{mg}^{-1}$. Over 100 cycles, the capacity fades to $353.4 \mathrm{mAh} \mathrm{g}^{-1}$ thus retaining $87 \%$ of its initial capacity. The CE consistently remains over $99.5 \%$ throughout the 100 cycles indicating minimal active material loss.

In order to better understand the chemical transformations taking place during the battery operation, first-principles DFT calculations were performed. The reactions from these calculations are outlined in Scheme 1. From the voltage profile in Figure 1c, it can be seen that the stages I and II each correspond to $70 \mathrm{mAh} \mathrm{g}^{-1}$ capacity, indicating they are both one electron process (the one electron capacity is $69.67 \mathrm{mAh} \mathrm{g}^{-1}$ ), while plateau III is a 4-electron process 
with $\sim 265 \mathrm{mAh} \mathrm{g}^{-1}$ capacity. For plateau I, we started by calculating the equilibrium geometry of PMTT 1, shown in Figure 2a. The LUMO for this geometry is indicated in Figure 2b. LUMO levels are mostly localized along the S-S chain, which means that the electrochemical reaction will be initiated along the chain. Interestingly, after adding one electron, the S-S bond marked in Scheme 1 becomes unstable (Figure S3, ESI), indicating the one electron process is dissociative. This could lead to the formation of the $\mathrm{C}_{5} \mathrm{H}_{10} \mathrm{NCSS}$ - radical or the radical 3, However, radical 3 is around $0.5 \mathrm{eV}$ lower in energy, and thus is preferred. In other words, after the first electron process, the PMTT molecule breaks up taking a Li-ion, forming the LiPMDTC 2 and 3 . Tracing the LUMO energy change provides the difference in reduction potential between the different organic compounds. ${ }^{27,}{ }^{28}$ As can be seen in Figure 2c, the LUMO energy difference of $0.54 \mathrm{eV}$ between $\mathbf{1}$ and $\mathbf{3}$ corresponds to the voltage drop to $2.55 \mathrm{~V}$ from the OCV for the first plateau. Next, 3 will continue to react with $\mathrm{Li}^{+}$. However, no dissociative behavior is observed, suggesting that this molecule can take one $\mathrm{Li}^{+}$without breaking up thus yielding 4 . The LUMO energy change of $0.25 \mathrm{eV}$ from 3 to 4 roughly corresponds to the voltage gap between plateaus I and II. Moving from plateau II to III of the voltage profile, additional $\mathrm{Li}^{+}$will again cause the structure to be unstable (Figure S4, ESI), indicating another dissociative reaction along the bond marked in 4. This yields the LiPMDTC 2 and the lithium persulfide radical 5. This radical upon further lithiation in the presence of excess $\mathrm{Li}^{+}$results in the formation of two $\mathrm{Li}_{2} \mathrm{~S} 6$. It is also possible that two lithium persulfide radicals disproportionate to yield lithium tetrasulfide $\left(\mathrm{Li}_{2} \mathrm{~S}_{4}\right)$ which eventually gets lithiated to yield the $\mathrm{Li}_{2} \mathrm{~S}$. The $0.39 \mathrm{eV}$ increase between $\mathbf{4}$ and $\mathbf{2}$ aligns with plateau III occurring at $2.1 \mathrm{~V}$. Additionally, it is interesting to note that $\mathbf{2}$ can alternatively exist in its mesomeric form $7\left(\mathrm{Li}_{2} \mathrm{PMDTC}^{+}\right)$with a positive nitrogen center in the presence of excess $\mathrm{Li}^{+}$owing to the $\mathrm{N}$-electron flow from nitrogen to sulfur through planar delocalized $\pi$ - 
orbitals which will be discussed later. ${ }^{29}$ As for PMTH, the pathway remains relatively unaltered ( see Figure S5, ESI) with the exception of higher order polysulfides formed in the penultimate step before the reduction to $\mathrm{Li}_{2} \mathrm{~S}$.

In order to validate the proposed reaction mechanism, XPS was performed on the electrodes extracted from cells at different stages of cycling as in the S 2p spectrum shown in Figure 3a. The PMTT-CNT electrode at OCV exhibits 3 pairs of doublets. The 2p3/2 peak centered at $162.2 \mathrm{eV}$ corresponds to sulfur in the $\mathrm{C}=\mathrm{S}$ and the peaks at $164.2 \mathrm{eV}$ and $164.3 \mathrm{eV}$ correspond to sulfur in C-S and the bridging sulfur respectively. ${ }^{30}$ Upon discharging to $\sim 2.1 \mathrm{~V}$, we observe the formation of the LiPMDTC 2 (2p3/2 at $162.2 \mathrm{eV}$, marked blue) along with its mesomeric form 7 ( $2 \mathrm{p}_{3 / 2}$ at $161.6 \mathrm{eV}$, marked red) as described to exist in literature. ${ }^{30,31}$ We also observe the $2 \mathrm{p}_{3 / 2}$ of the terminal (green) and bridging (orange) sulfur of $\mathrm{Li}_{2} \mathrm{~S}_{4}$ at $162.2 \mathrm{eV}$ and $163.6 \mathrm{eV}$ respectively. ${ }^{32,33}$

This confirms the reaction pathway of $\mathbf{4}$ yielding $\mathbf{2}$ and $\mathbf{5}$. Upon fully discharging, both the mesomeric forms 2 with $2 \mathrm{p}_{3 / 2}$ at $163.0 \mathrm{eV}$ and 7 at $161.4 \mathrm{eV}$ are evident along with $\mathrm{Li}_{2} \mathrm{~S}$ (2 $\mathrm{p}_{3 / 2}$ at $161.0 \mathrm{eV}$, green) confirm the fully discharged products of PMTT. The binding energies for $\mathrm{Li}_{2} \mathrm{~S}_{4}$ and $\mathrm{Li}_{2} \mathrm{~S}$ agree well with those in literature albeit being slightly higher (reason described in a later section). ${ }^{17,32-35}$ Upon charging to $2.4 \mathrm{~V}$, a state similar to that during half discharge is observed, showing the presence of LiPMDTC and $\mathrm{Li}_{2} \mathrm{~S}_{4}$ which converts to PMTT upon fully charging. Small unresolved components observed beyond $166 \mathrm{eV}$ correspond to sulfate/thiosulfate species formed on oxidation of $\mathrm{Li}_{2} \mathrm{~S}_{2} \mathrm{Li}_{2} \mathrm{~S}_{4}$ while loading XPS samples on the instrument. ${ }^{35}$

Chemical transformations were tracked using XRD as shown in Figure 3b. On comparing the XRD diffractogram of the PMTT-CNT composite with that of commercial PMTT 
powder, we can see all the peaks of PMTT appear along with the (002) carbon peak from CNT thus indicating that no chemical transformation occurs during the cathode preparation process. Upon discharge, new peaks between $2 \theta$ of $21^{\circ}-31^{\circ}$ and $39^{\circ}-45^{\circ}$ appear signaling the formation of LiPMDTC. Distinct $\mathrm{Li}_{2} \mathrm{~S}$ peaks are absent in the spectrum despite its presence in the XPS S 2p spectrum suggesting that the $\mathrm{Li}_{2} \mathrm{~S}$ might be formed in its amorphous phase. Upon charging, the PMTT reappears but with broader peaks having lower intensities signifying a change in particle size and crystallinity on cycling. Further investigation was carried out in the form of FTIR spectroscopy. The defining bands in the spectrum (Figure 3c) occur in the 1500-1400 $\mathrm{cm}^{-1}$ region corresponding to $\mathrm{N}-\mathrm{C}$ bond vibrations, from $1170-1115 \mathrm{~cm}^{-1}$ for the $\mathrm{C}=\mathrm{S}$ bond and from 1030-930 $\mathrm{cm}^{-1}$ for $\mathrm{C}(=\mathrm{S})-\mathrm{S}$ bond. ${ }^{29,36,37}$ On comparing the spectrum of the discharged state with that of the cathode we observe diminished intensity in the $\mathrm{N}-\mathrm{C}$ band and for those of the $\mathrm{C}=\mathrm{S}$ bond whereas, the C-S bond is still evident on discharge. This is caused by the prevalence of the mesomeric structure $\mathbf{7}$ which results in the loss of the single-bond character of the $\mathrm{N}-\mathrm{C}$ bond and the double-bond character of the $\mathrm{C}=\mathrm{S}$ bond while retaining the C-S bond. ${ }^{29,}{ }^{37}$ Upon recharging, the peak intensities are restored on the formation of PMTT. This reversibility is further validated by the ${ }^{1} \mathrm{H}-\mathrm{NMR}$ of the cathode (figure S6) after recharge which clearly shows that PMTT is reformed at the end of charge.

FTIR, as well as XPS data, strongly suggests the presence of the mesomeric form of the discharge compound LiPMDTC, i.e. $\mathrm{Li}_{2} \mathrm{PMDTC}^{+}$. Additionally, the excellent cycling performance prompted us to probe the possible interaction between $\mathrm{Li}_{2} \mathrm{PMDTC}^{+}$and the polysulfide intermediates formed during battery operation. It is likely that, the presence of excess $\mathrm{Li}^{+}$in the electrolyte can promote and stabilize the electron delocalization in $\mathrm{Li}_{2} \mathrm{PMDTC}^{+}$ without an electron transfer. This causes a dipole moment change in the molecule from 0.77 
Debye for LiPMDTC to 17.0 Debye for $\mathrm{Li}_{2} \mathrm{PMDTC}^{+}$leading to strong Coulombic interaction between $\mathrm{Li}_{2} \mathrm{PMDTC}^{+}$and the polysulfide/sulfide species present in the electrolyte as highlighted in Figure 4a which shows the interaction between $\mathrm{Li}_{2} \mathrm{PMDTC}^{+}$and $\mathrm{Li}_{2} \mathrm{~S}_{2}$ as a representative molecule. First-principles calculations were performed to determine the net charge transfer from the sulfide and polysulfide $\left(\mathrm{Li}_{2} \mathrm{~S}_{\mathrm{x}}, \mathrm{x}=1,2,4\right)$ formed out of the intermediate 5 to the positive nitrogen $\left(\mathrm{N}^{+}\right)$center in $\mathrm{Li}_{2} \mathrm{PMDTC}^{+}$. Figure $4 \mathbf{b}$ shows that the terminal sulfur of the electrolyte soluble $\mathrm{Li}_{2} \mathrm{~S}_{4}$ has much higher electron transfer compared to the solid $\mathrm{Li}_{2} \mathrm{~S}$ and $\mathrm{Li}_{2} \mathrm{~S}_{2}$ phases. Correspondingly, the nitrogen also experiences a loss in its positive charge character showing strong affinity for electrons from $\mathrm{Li}_{2} \mathrm{~S}$ and $\mathrm{Li}_{2} \mathrm{~S}_{4}$. These translate to heightened polysulfide attraction and thus their retention in the cathode during cycling, leading to stable cycle life.

Re-examination of S 2p XPS data in the discharged state and the half-charged state which is pertinent to inhibition of the polysulfide shuttle provides evidence to support this phenomenon. In the discharged state, the $\mathrm{S}^{2-}$ ion from $\mathrm{Li}_{2} \mathrm{~S}$ and $\mathrm{N}^{+}$center interaction leads to loss of negative charge on the sulfide causing shift in binding energy to $161.0 \mathrm{eV}$ from its reported value of 160.1 $\mathrm{eV}^{34}$ Similarly, in the half-charged state, the binding energy of the terminal sulfide group of $\mathrm{Li}_{2} \mathrm{~S}_{4}$ has its value shifted to $162.0 \mathrm{eV}$ from $161.5 \mathrm{eV}$. Further support is provided by the $\mathrm{N} 1 \mathrm{~s}$ XPS spectrum in Figure 4c. The peak for neutral nitrogen species of PMTT (Panel i) as well as LiPMDTC 2 (Panel ii and iii) occurs at $399.5 \mathrm{eV}$ while that of $\mathrm{N}^{+}$nitrogen species on discharge occurs at $400.5 \mathrm{eV}$. This is a downshift of $1.5 \mathrm{eV}$ from $\sim 402.0 \mathrm{eV}$ reported for quaternary nitrogen owing to the charge transfer from the electron rich $\mathrm{S}^{2-}$ to the $\mathrm{N}^{+}$center as expected from the calculation. ${ }^{38,39}$ A shift of $0.5 \mathrm{eV}$ to $401.5 \mathrm{eV}$ is also observed for the interaction of $\mathrm{Li}_{2} \mathrm{~S}_{4}$ in the half-charged state (Panel iii). It is interesting to note that only a part of the discharge product exists as $\mathrm{Li}_{2} \mathrm{PMDTC}^{+}$probably based on the concentration of $\mathrm{Li}^{+}, \mathrm{S}^{2-}$ and salt anion in the 
electrolyte available for interaction at any given site. Steric hindrances might also limit the interaction at certain sites.

On unraveling the chemical transformations in the cathode, we turn to their physical manifestations of morphology and structural changes analyzed through SEM. SEM image of the PMTT-CNT composite (Figure 5a) shows that commercial PMTT particles are several microns in length enabling them to be successfully trapped in the web of the interwoven CNT network. This enables the use of commercial powders without the need for processing making the cathode preparation simple, efficient and easily scalable. The entrapment of the PMTT also facilitates excellent electron transfer into the particles enabling excellent performance without high overpotentials despite large particle size. On discharging, at the end of plateau I (Figure 5b), we can see that the particles have mostly eroded away leading to the deposition of intermediates in the CNT network. On further discharge beyond plateau II (Figure 5c), we can observe polysulfide deposits on CNT fibrils which transform on lithiation into solid discharge products (Figure 5d) completely covering the CNT network. ${ }^{40}$ These close deposits also assist in strengthening the Coulombic interactions thus inhibiting the leaching of sulfur species into the electrolyte. In the half-charged state (Figure 5e), the polysulfide species are successfully sequestered by the CNT network which enables the regrowth of PMTT on delithiation (Figure 5f). The PMTT formed on recharge are of much smaller particle size as evidenced by the XRD spectrum. The conformal deposition of PMTT enables excellent confinement while providing sufficient access to the electrolyte in the cathode thus prolonging cycle life and enabling operation with low electrolyte-active material ratios.

Interestingly, polysulfide formation is also clearly discernable on visually inspecting the separators from opened cells. While those at OCV and end of plateau I (Figures S7a and S7b in 
ESI respectively) are clear, a yellowish tinge is visible for the extracted separator after plateau II (Figure S7c, ESI) providing support to our XPS observations and reaction mechanism. It turns clear again on full discharge (Figure S7d, ESI) while exhibiting the yellow tint at the halfrecharged state (Figure S7e, ESI). It turns clear again on full recharge (Figure S7f, ESI). These results further confirm the formation of $\mathrm{Li}_{2} \mathrm{~S}_{4}$ in the middle of discharge and charge, however the strong Coulombic interaction between $\mathrm{Li}_{2} \mathrm{PMDTC}^{+}$and $\mathrm{Li}_{2} \mathrm{~S}_{4}$ results in negligible loss of intermediate polysulfides.

After gaining insight into the physical and chemical changes occurring in thiuram cathodes we explore the potential of this chemistry in the form of a higher order polysulfide analog of PMTT namely, PMTH. There are two more sulfur atoms in the middle of PMTH, which can take 4 more electrons per molecule than PMTT as shown in Figure S5. Like PMTT, PMTH is also commercially available and has similar physical properties and can yield a higher specific capacity of $597 \mathrm{mAh} \mathrm{g}^{-1}$ considering a 10e- reduction reaction along with a theoretical specific energy of 1,300 Wh $\mathrm{kg}^{-1}$ which makes it more suitable for practical applications. The cycling performance on employing a PMTH-CNT cathode at C/5 is displayed in Figure 6a. The cathode exhibits a capacity of $539.4 \mathrm{mAh} \mathrm{g}^{-1}$ in the first discharge which increases to $575 \mathrm{mAh} \mathrm{g}^{-}$ ${ }^{1}$ by the $8^{\text {th }}$ cycle which corresponds to $96 \%$ of the theoretical capacity. The capacity increase could be due to electrochemical activation of large PMTH particles in the electrode. The cathode cycles with a high CE of $>99.4 \%$ after the first cycle while retaining $85 \%$ of its initial capacity after 100 cycles. The Li anode from this cell (Figure S8, ESI), upon inspection, reveals that anode corrosion is the cause for premature failure of this cell. ${ }^{41,42}$ On reinvigorating the cathode in a new cell with fresh Li anode, we can see stable performance over 150 more cycles thus establishing the durability of this cathode material. On surveying the voltage profile for PMTH 
(Figure S9, ESI) and the CV (Figure S10, ESI) we can see that it behaves similar to PMTT, except the lowest discharge plateau is much longer than that of PMTT because of more sulfur atoms in the middle of PMTH forming more $\mathrm{Li}_{2} \mathrm{~S}$ in the discharge. PMTH displays promising rate performance (Figure S11, ESI) affording about $550 \mathrm{mAh} \mathrm{g}^{-1}$ at C/5, $510 \mathrm{mAh} \mathrm{g}^{-1}$, and 486 $\mathrm{mAh} \mathrm{g}^{-1}$ at practical rates of $\mathrm{C} / 2$ and $1 \mathrm{C}$ respectively.

To gauge the practical usability of this class of active materials, it is necessary to test the battery with high areal capacity while utilizing low amount of electrolyte to estimate the cell level energy density as highlighted by recent literature. ${ }^{15,16,43}$ We tested high loading cells employing 2 cathode films while utilizing an electrolyte to $\mathrm{PMTH}$ ratio of $3 \mu \mathrm{L} \mathrm{mg}{ }^{-1}$ at C/10. Figure 6b shows the cycle performance of one such cell. In the first cycle, the cell delivers 5.3 mAh $\mathrm{cm}^{-2}$ which corresponds to a specific energy of $1,156 \mathrm{Wh} \mathrm{kg}^{-1}$. Even at the cathode level, a specific energy of nearly $765 \mathrm{Wh} \mathrm{kg}^{-1}$ can be achieved which is much greater than the theoretical specific energy of layered oxide cathodes used in commercial Li-ion batteries. ${ }^{3}$ This cell delivers a specific capacity of $530 \mathrm{mAh} \mathrm{g}^{-1}$ in the first cycle corresponding to a material utilization of 88\%. For comparison, this PMTH cathode was pitted against a sulfur cathode with an equivalent capacity loading operating at an electrolyte to sulfur ratio of 5 as well as $10 \mu \mathrm{L} \mathrm{mg}^{-1}$ (Figure S12, ESI). At $5 \mu \mathrm{L} \mathrm{mg}^{-1}$, the performance of sulfur is far inferior with a utilization of only $43 \%$ coupled with high overpotentials. Despite cycling at an electrolyte to sulfur ratio of $10 \mu \mathrm{L} \mathrm{mg}^{-1}$ only $59 \%$ of the active material is utilized with a CE of only $90 \%$ due to shuttle effect. Whereas, it is evident that PMTH offers much better material utilization, higher energy density as well as improved CE of 98\% while minimizing the polysulfide shuttle. This demonstrates the versatility of thiuram chemistry to operate in low electrolyte conditions which is crucial for its commercial application. Also, the cell is able to deliver over $4 \mathrm{mAh} \mathrm{g}^{-1}$ of areal capacity over this period 
which is comparable to Li-ion cells. ${ }^{44}$ While the calendar life of the high loading cell is limited, we note that the cathode is as yet un-optimized and utilizes commercially derived materials. Thus, advanced cathode design, as well as advancements in this field, could certainly propel this cathode to outperform current Li-ion technology.

\section{Conclusion}

This study utilizes abundant and cheap thiuram polysulfides as cathode materials for lithium batteries. Binder-free cathodes fabricated through a facile and scalable process shows high material utilization and promising battery performance. First-principles calculations combined with materials characterization through XPS, XRD, and FTIR unveils the underlying chemical reactions occurring during battery cycling. Further examination reveals the strong Coulombic interactions between polysulfide species and mesomeric form of the discharge product LiPMDTC with a positive nitrogen center. This enables stable cycle life. This unique chemistry of thiuram polysulfides presented here highlights the relatively untapped potential of utilizing organic molecules that can serve the dual purpose of active materials as well as polysulfide and sulfide anchors for energy-dense lithium batteries. We hope that this work inspires the development of cathodes that exploit this chemistry and also prompts further organosulfur chemistry that could go beyond the $1,156 \mathrm{Wh} \mathrm{kg}^{-1}$ demonstrated here in our quest for new batteries to power our future.

\section{References}

1. M. Armand and J. M. Tarascon, Nature, 2008, 451, 652-657.

2. J. B. Goodenough and K.-S. Park, J. Am. Chem. Soc., 2013, 135, 1167-1176.

3. A. Manthiram, J. Phys. Chem. Lett., 2011, 2, 176-184.

4. P. G. Bruce, S. A. Freunberger, L. J. Hardwick and J.-M. Tarascon, Nat. Mater., 2012, 11, 19-29.

5. J. B. Goodenough, Energy Environ. Sci., 2014, 7, 14-18.

6. A. Manthiram, Y. Fu and Y.-S. Su, Acc. Chem. Res., 2012, 46, 1125-1134.

7. A. Manthiram, Y. Fu, S.-H. Chung, C. Zu and Y.-S. Su, Chem. Rev., 2014, 114, 11751-11787. 
8. Q. Pang, X. Liang, C. Y. Kwok and L. F. Nazar, Nat. Energy., 2016, 1, 16132.

9. Q. Pang, X. Liang, C. Y. Kwok and L. F. Nazar, J. Electrochem. Soc., 2015, 162, A2567-A2576.

10. D. Lv, J. Zheng, Q. Li, X. Xie, S. Ferrara, Z. Nie, L. B. Mehdi, N. D. Browning, J.-G. Zhang, G. L. Graff, J. Liu and J. Xiao, Adv. Energy Mater., 2015, 5, 1402290.

11. J. Brückner, S. Thieme, H. T. Grossmann, S. Dörfler, H. Althues and S. Kaskel, J. Power Sources, 2014, 268, 82-87.

12. M. Hagen, S. Dörfler, P. Fanz, T. Berger, R. Speck, J. Tübke, H. Althues, M. J. Hoffmann, C. Scherr and S. Kaskel, J. Power Sources, 2013, 224, 260-268.

13. J. Zheng, D. Lv, M. Gu, C. Wang, J.-G. Zhang, J. Liu and J. Xiao, J. Electrochem. Soc., 2013, 160, A2288-A2292.

14. M. Hagen, P. Fanz and J. Tübke, J. Power Sources, 2014, 264, 30-34.

15. M. Hagen, D. Hanselmann, K. Ahlbrecht, R. Maça, D. Gerber and J. Tübke, Adv. Energy Mater., 2015, 5, 1401986.

16. C. Fu and J. Guo, Curr. Opin. Chem. Eng., 2016, 13, 53-62.

17. M. Wu, Y. Cui, A. Bhargav, Y. Losovyj, A. Siegel, M. Agarwal, Y. Ma and Y. Fu, Angew. Chem. Int. Ed., 2016, 55, 10027-10031.

18. S. Chen, F. Dai, M. L. Gordin, Z. Yu, Y. Gao, J. Song and D. Wang, Angew. Chem., 2016, 128, 43034307.

19. Y. Liang, Z. Tao and J. Chen, Adv. Energy Mater., 2012, 2, 742-769.

20. P. Novák, K. Müller, K. S. V. Santhanam and O. Haas, Chem. Rev., 1997, 97, 207-282.

21. M. Liu, S. J. Visco and L. C. De Jonghe, J. Electrochem. Soc., 1989, 136, 2570-2575.

22. M. Liu, S. J. Visco and L. C. De Jonghe, J. Electrochem. Soc., 1990, 137, 750-759.

23. S. J. Visco, M. Liu and L. C. De Jonghe, J. Electrochem. Soc., 1990, 137, 1191-1192.

24. M. Geyser and W. J. McGill, J. Appl. Polym. Sci., 1996, 60, 425-430.

25. Y. Zhao and D. G. Truhlar, Theor. Chem. Acc., 2008, 120, 215-241.

26. G. Speranza, L. Minati and M. Anderle, J. Appl. Phys., 2007, 102, 043504.

27. Z. Song, Y. Qian, X. Liu, T. Zhang, Y. Zhu, H. Yu, M. Otani and H. Zhou, Energy Environ. Sci., 2014, 7, 4077-4086.

28. Z. Song, H. Zhan and Y. Zhou, Angew. Chem. Int. Ed., 2010, 49, 8444-8448.

29. H. C. Brinkhoff and A. M. Grotens, Recl. Trav. Chim. Pays-Bas, 1971, 90, 252-257.

30. P. Morf, F. Raimondi, H.-G. Nothofer, B. Schnyder, A. Yasuda, J. M. Wessels and T. A. Jung, Langmuir, 2006, 22, 658-663.

31. F. von Wrochem, D. Gao, F. Scholz, H.-G. Nothofer, G. Nelles and J. M. Wessels, Nat. Nanotechnol., 2010, 5, 618-624.

32. X. Liang, C. Hart, Q. Pang, A. Garsuch, T. Weiss and L. F. Nazar, Nat. Commun., 2015, 6, 5682.

33. Q. Pang, D. Kundu and L. F. Nazar, Mater. Horiz., 2016, 3, 130-136.

34. Y. Fu, C. Zu and A. Manthiram, J. Am. Chem. Soc., 2013, 135, 18044-18047.

35. Q. Pang and L. F. Nazar, ACS Nano, 2016, 10, 4111-4118.

36. M. M. Coleman, J. L. Koenig and J. R. Shelton, J. Polym. Sci., Part B: Polym. Phys., 1974, 12, 10011013.

37. S. Sánchez-Cortés, C. Domingo, J. V. García-Ramos and J. A. Aznárez, Langmuir, 2001, 17, 11571162.

38. R. K. Blundell and P. Licence, Phys. Chem. Chem. Phys., 2014, 16, 15278-15288.

39. S. Kabir, K. Artyushkova, A. Serov, B. Kiefer and P. Atanassov, Surf. Interface Anal., 2016, 48, 293300.

40. A. Bhargav, M. Wu and Y. Fu, J. Electrochem. Soc., 2016, 163, A1543-A1549.

41. L. Qie, C. Zu and A. Manthiram, Adv. Energy Mater., 2016, 6, 1502459.

42. R. Cao, W. Xu, D. Lv, J. Xiao and J.-G. Zhang, Adv. Energy Mater., 2015, 5, 1402273. 
43. B. D. McCloskey, J. Phys. Chem. Lett., 2015, 6, 4581-4588.

44. K. G. Gallagher, S. E. Trask, C. Bauer, T. Woehrle, S. F. Lux, M. Tschech, P. Lamp, B. J. Polzin, S. Ha, B. Long, Q. Wu, W. Lu, D. W. Dees and A. N. Jansen, J. Electrochem. Soc., 2016, 163, A138A149.

\section{Acknowledgements}

This work was supported by the startup grant from Purdue School of Engineering and Technology and Department of Mechanical Engineering at Indiana University-Purdue University Indianapolis. We would like to acknowledge the Integrated Nanosystems Development Institute (INDI) for use of their Bruker D8 Discover XRD Instrument, which was awarded through the NSF grant MRI-1429241 and for use of their JEOL7800F Field Emission SEM, which was awarded through NSF grant MRI-1229514. We thank the Department of Chemistry and Chemical Biology at IUPUI for the use of their FTIR facility. We also thank the Nanoscale Characterization Facility at Indiana University for XPS measurements. YM would like to acknowledge the support from the Materials Science and Engineering Centre at the University of Wisconsin-Eau Claire.

\section{Author contributions}

A.B. proposed the concept of the battery and did the main measurements and analysis under the Y.F’s supervision. Y.M. performed the computational studies. K.S. assisted in cathode preparation. Y.C assisted in acquiring SEM data. Y.L. collected and assisted in the analysis of XPS data. A.B., Y.F., and Y.M. prepared the manuscript. All the authors discussed the results and commented on the manuscript.

\section{Competing interests}

The authors declare no competing financial interests. 


\section{Corresponding Authors}

yongfu@iupui.edu (Y.Fu)

yingma@uwec.edu (Y. Ma) 
a)

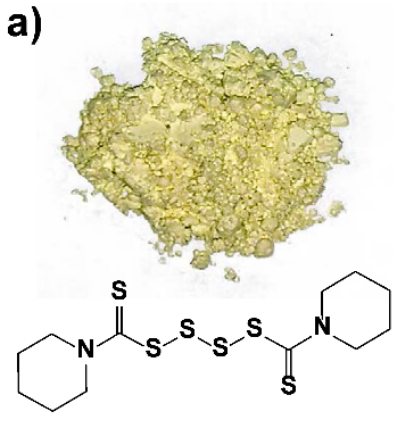

Dipentamethylene thiuram tetrasulfide

c) (PMTT)
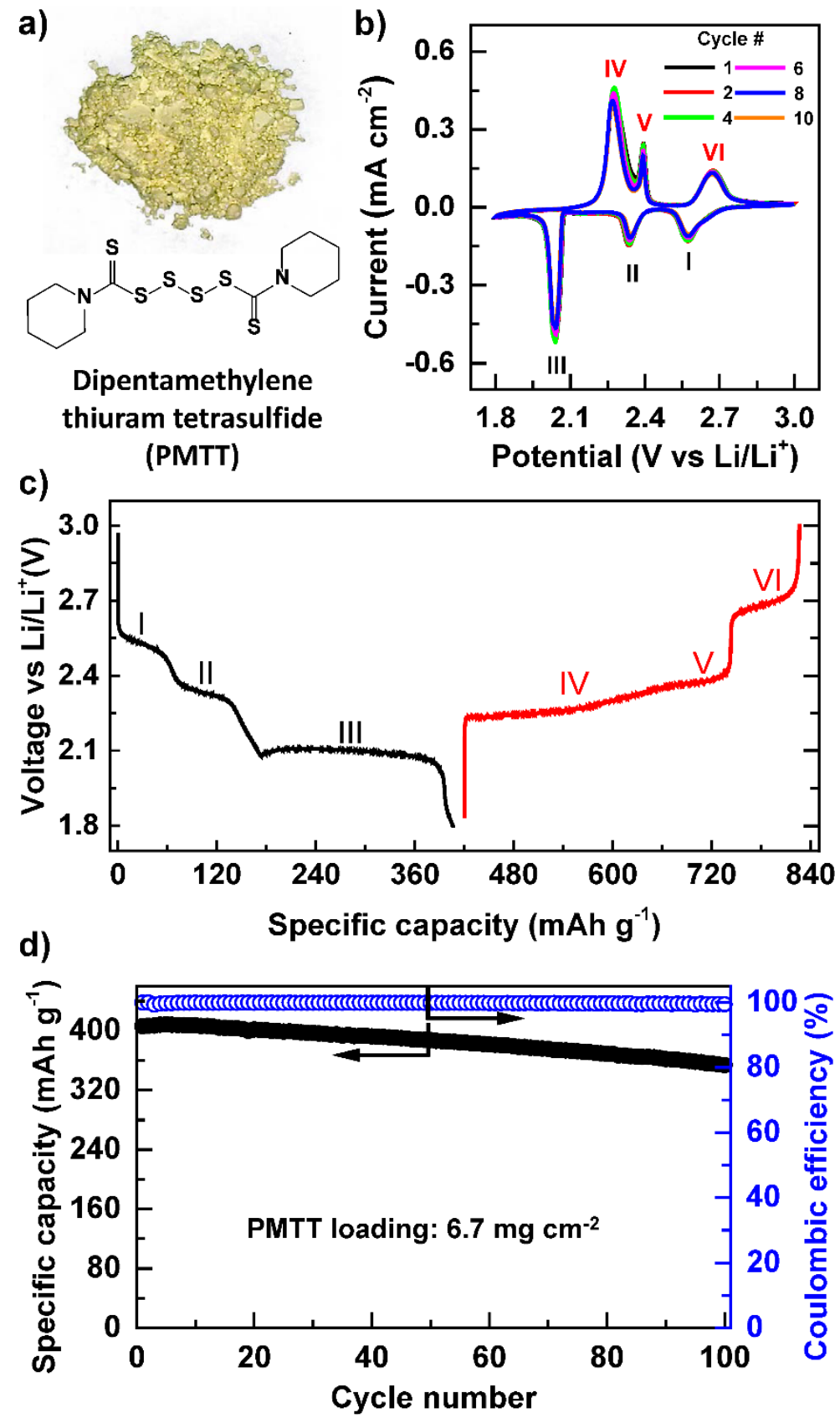

Figure 1. (a) Optical image of commercial PMTT powder along with its chemical structure; (b) Cyclic voltammetry (CV) of PMTT-CNT cathode performed at $0.05 \mathrm{mV} \mathrm{s}^{-1}$; (c) Voltage profile of the first cycle of PMTT-CNT cathode cycled at C/5 and (d) the corresponding cycle performance. The active material (PMTT) loading on the cathode was $6.7 \mathrm{mg} \mathrm{cm}^{-2}$ and the rate was based on PMTT mass in the cathode with $1 \mathrm{C}=418 \mathrm{~mA} \mathrm{~g}^{-1}$. 


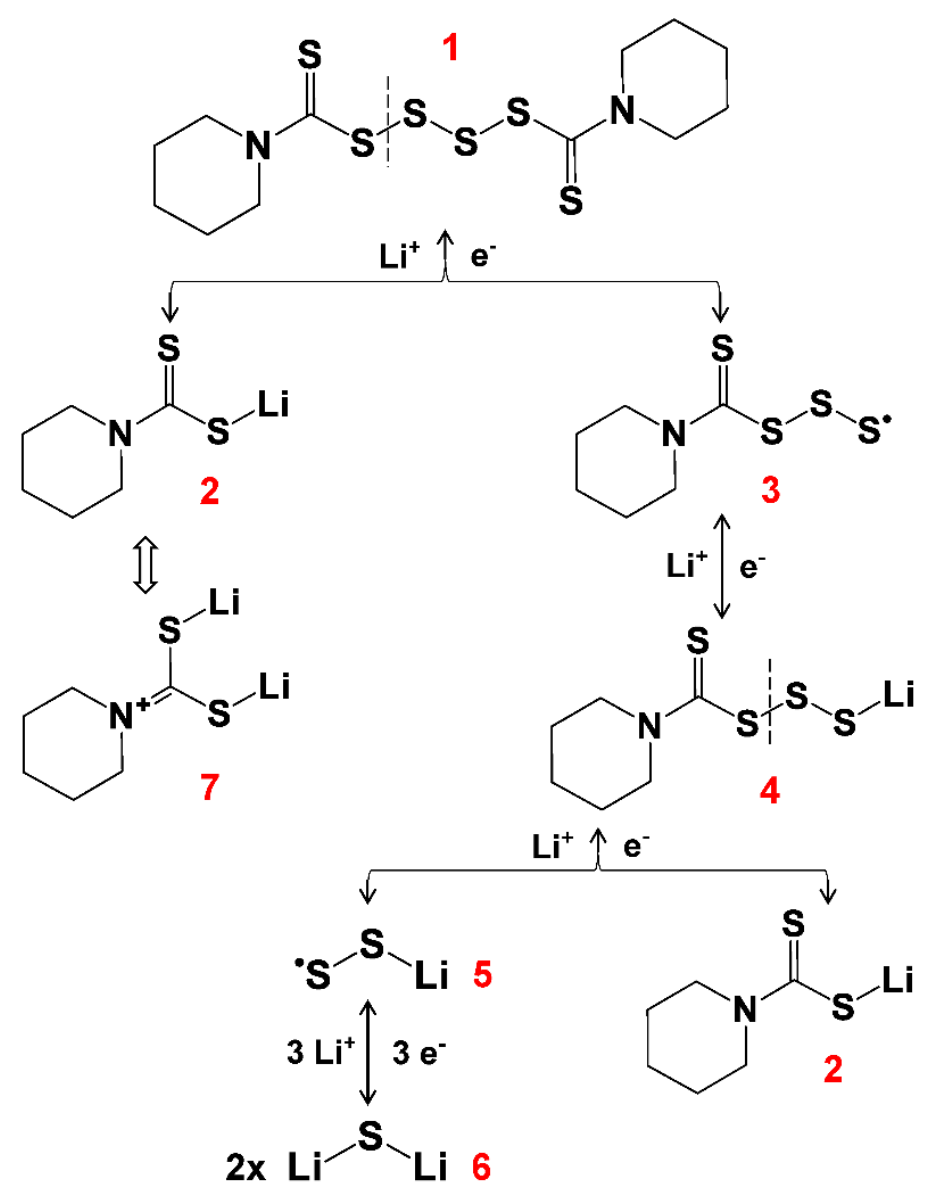

Scheme 1. Redox reactions of PMTT during battery cycling. See text for details. 
a)
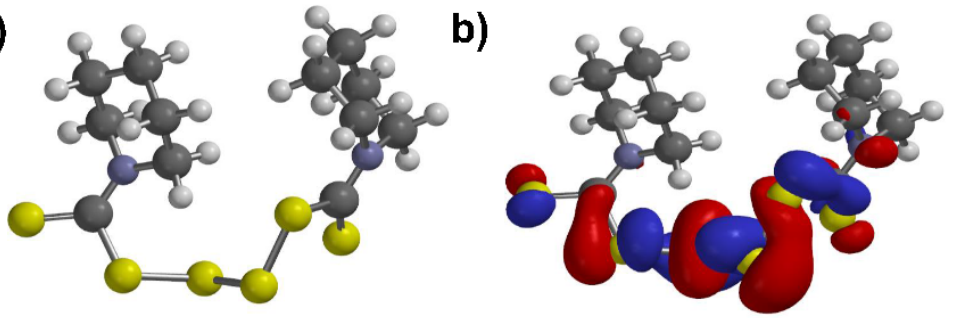

c)

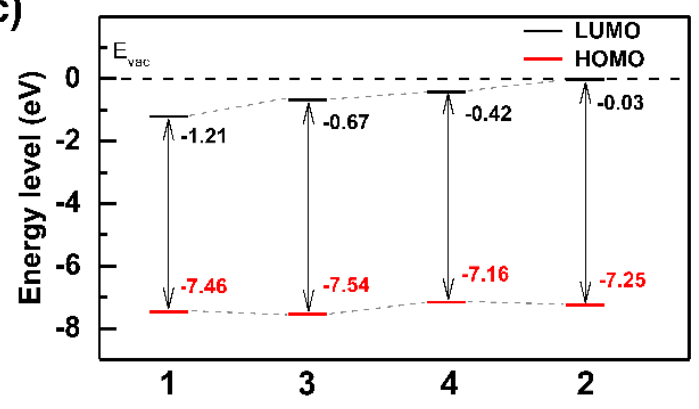

Figure 2. (a) Equilibrium structure of PMTT along with its (b) LUMO configuration, where the blue color indicates a positive phase whereas the red color refers to a negative phase. (c) LUMO/HOMO energy levels of the different intermediates formed during discharge/charge. These numbers correspond to those in Scheme 1. 

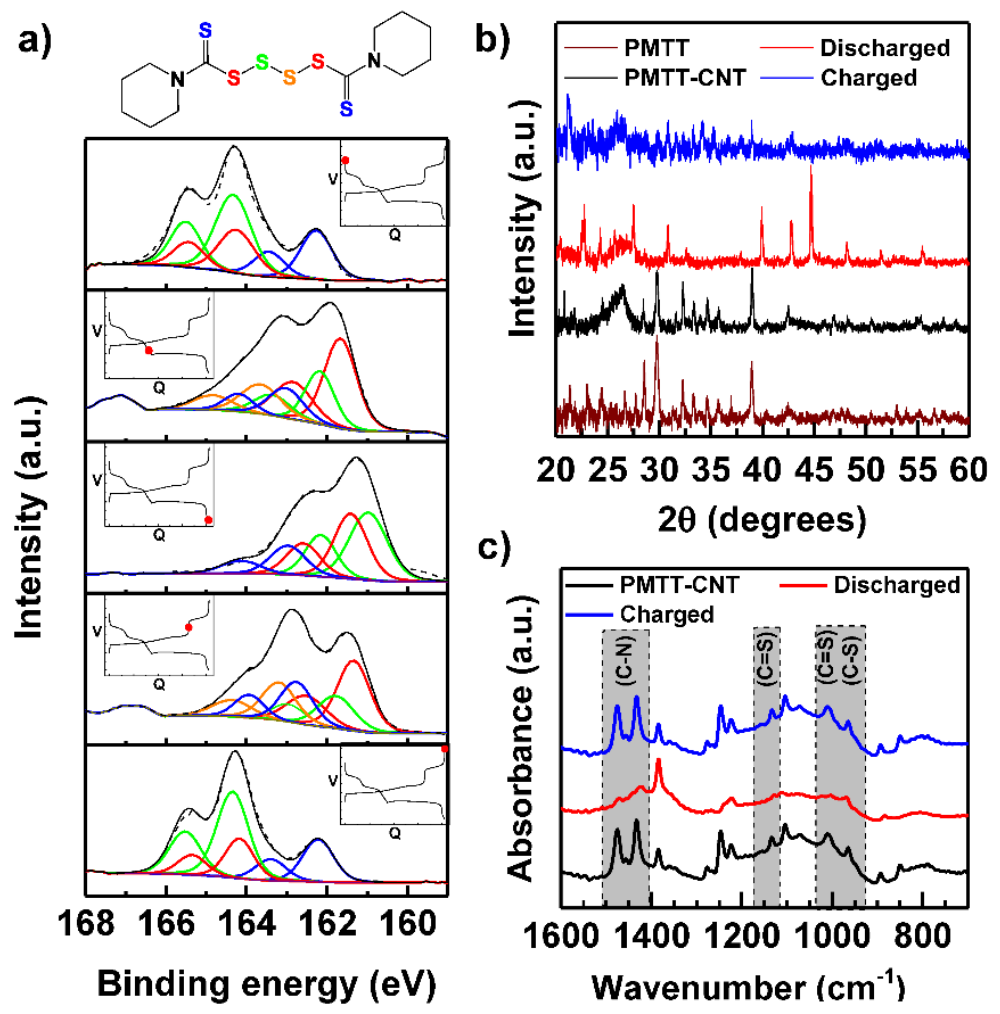

Figure 3. (a) Sulfur 2p XPS spectrum of PMTT cathode collected at different stages of cycling as indicated in the insert figures. The color of the sulfur labeled in the structure is a guide to the sulfur deconvoluted in the spectrum. (b) XRD and (c) FTIR spectrum of the cathode at different states of cycling. The bond ascribed to the different bands are indicated in the FTIR spectrum. 
a)

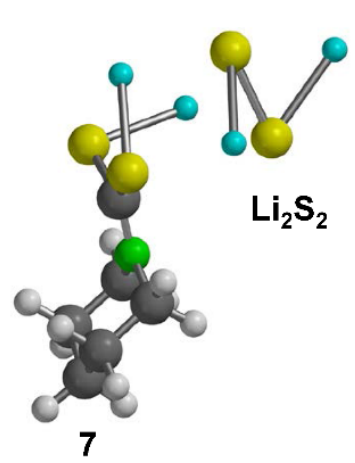

b)

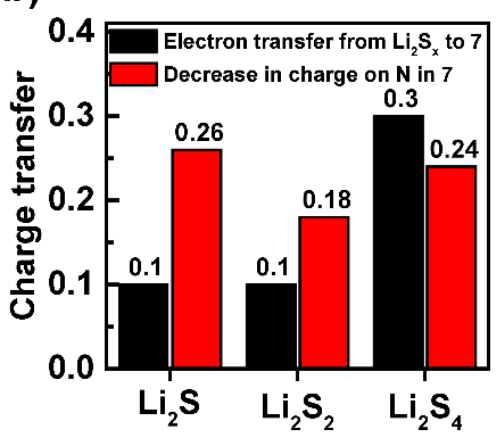

c)

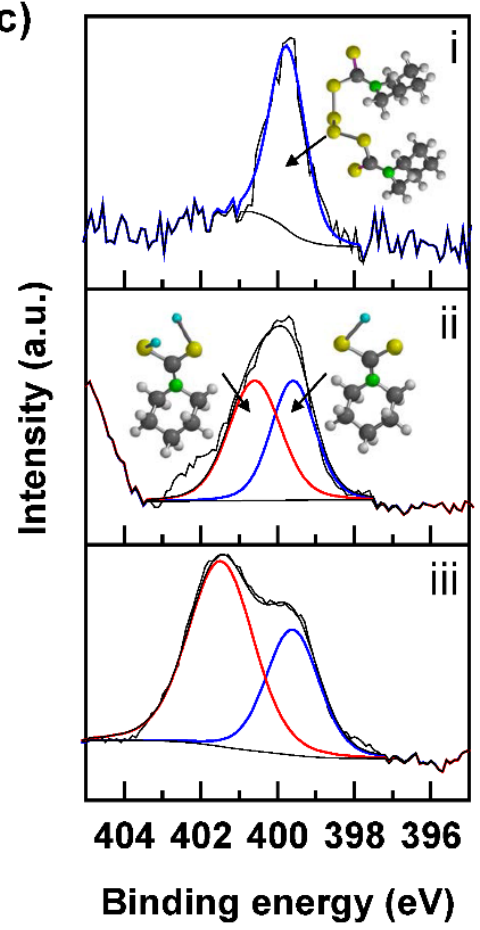

Figure 4. (a) Schematic showing the position of interaction between $\mathrm{Li}_{2} \mathrm{~S}_{2}$ and the positive $\mathrm{N}$ center of the ring along with (b) first-principles calculations of charge loss by different polysulfides with charge gain by $\mathrm{N}$ in $\mathrm{Li}_{2} \mathrm{PMDTC}^{+}$. (c) Nitrogen 1s XPS spectrum of PMTT cathode at OCV (i), fully discharged (ii) and half-charged (iii) state. 


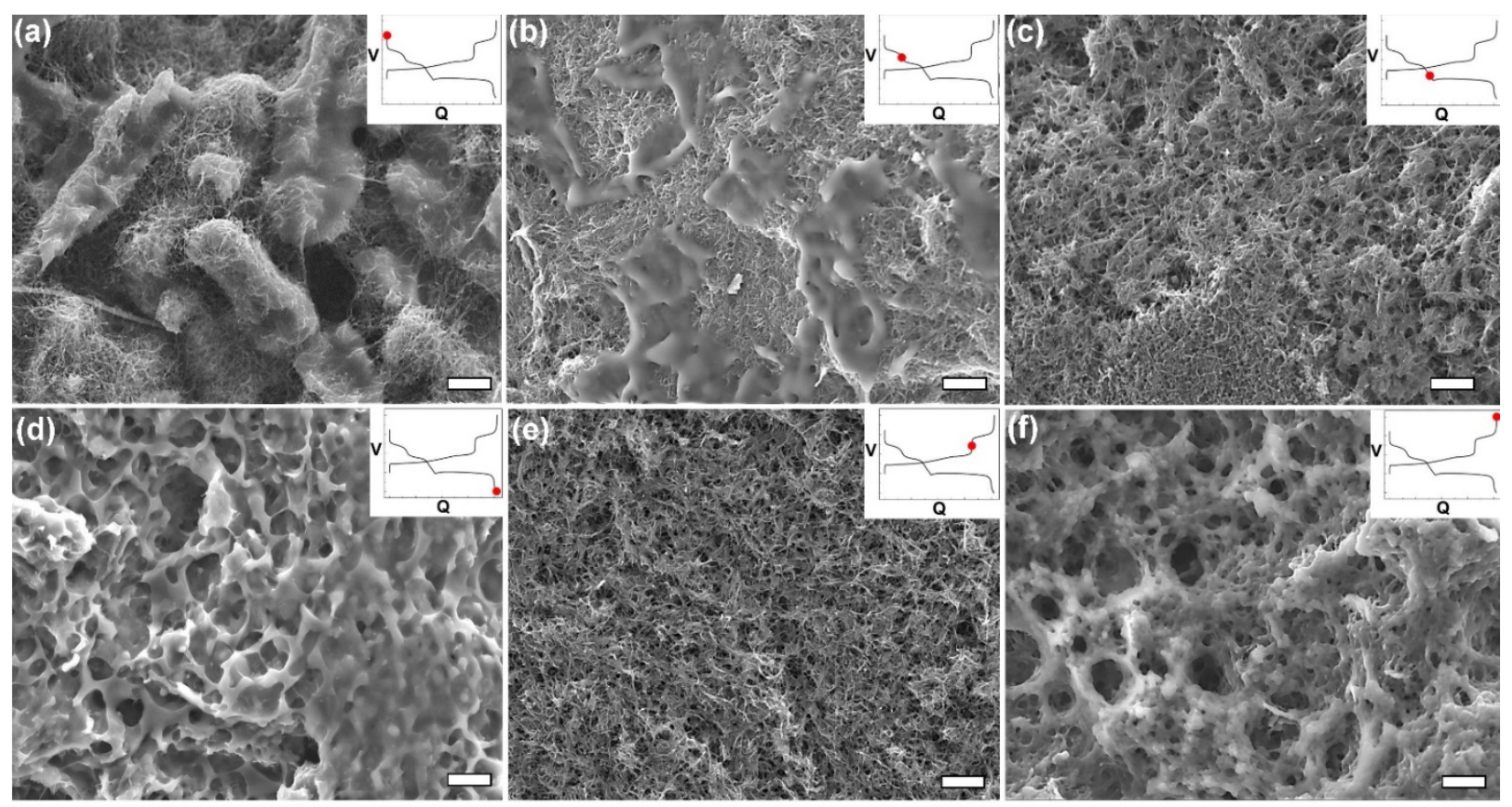

Figure 5. SEM images of the PMTT-CNT cathode taken at different stages of cycling as represented by the insert figure. All scale bars represent $1 \mu \mathrm{m}$. 

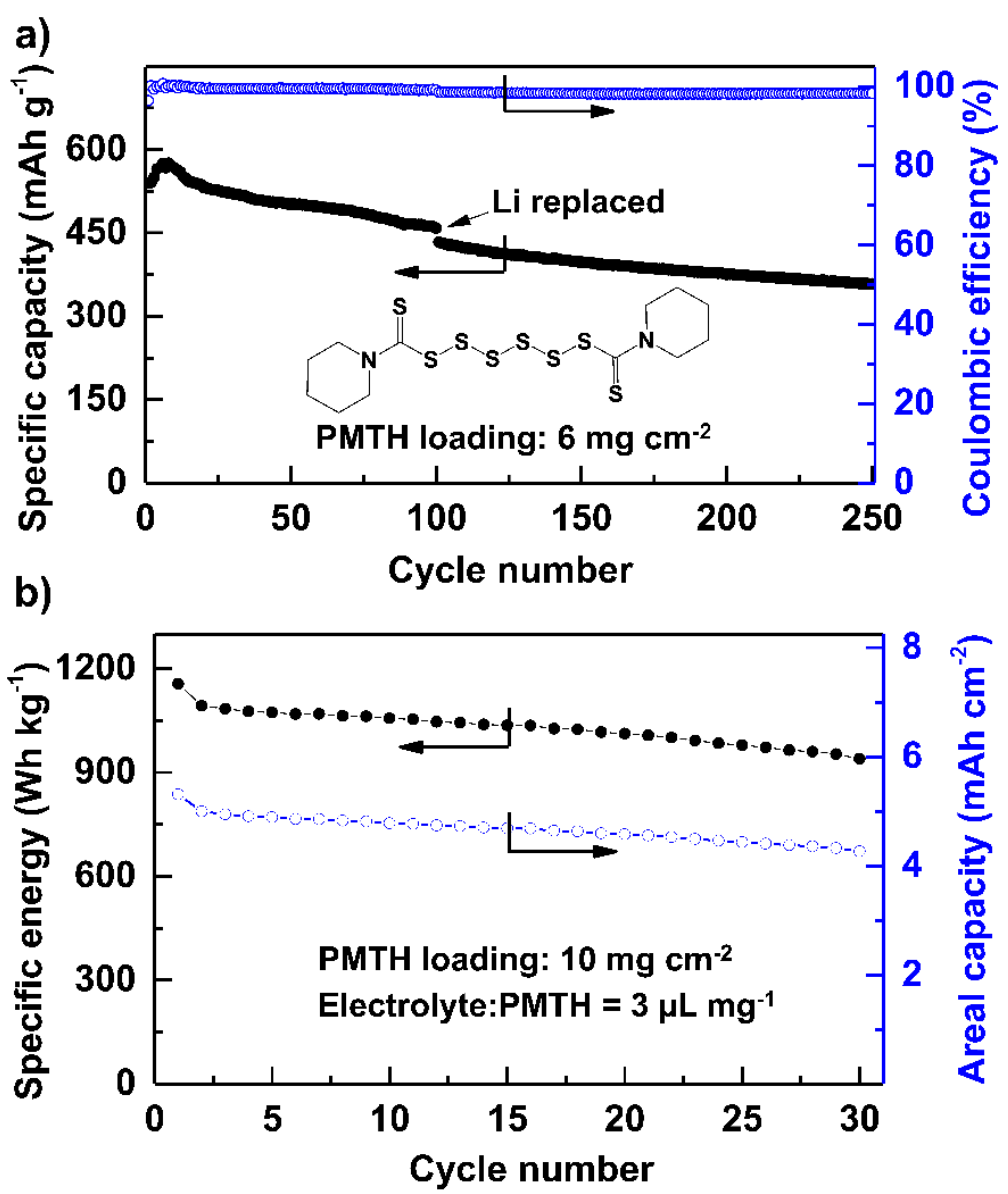

Figure 6. (a) Cycle performance of PMTH-CNT cathode cycled at C/5. The active material (PMTH) loading on the cathode was $6 \mathrm{mg} \mathrm{cm}^{-2}$. Li anode was replaced at the end of $100^{\text {th }}$ discharge. (b) A high loading, low electrolyte: PMTH ratio cell cycled at C/10 to demonstrate the practical capability of PMTH cathode. The cycling rate was based on PMTH mass in the cathode with $1 \mathrm{C}=597 \mathrm{~mA} \mathrm{~g}^{-1}$. 


\section{Table of contents}

Thiuram-type organopolysulfides show three discharge plateaus and high material utilization (up to 97\%) throughout cycling. The mesomeric form of lithium pentamethylene dithiocarbamate with a positive nitrogen center, formed in the discharge, can act as polysulfide and sulfide anchors through strong Coulombic interactions thus enabling long cycle life.

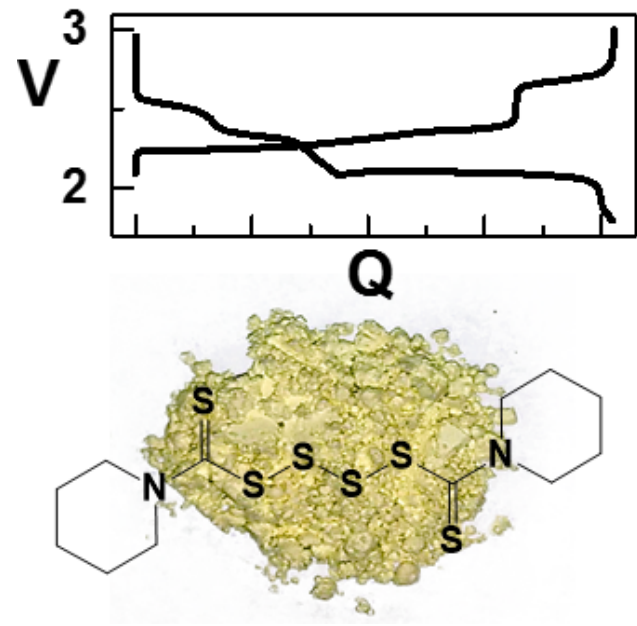




\section{Electronic Supporting Information (ESI)}

\section{Unique Chemistry of Thiuram Polysulfides Enable Energy Dense Lithium Batteries}

Amruth Bhargav, Ying Ma*, Kollur Shashikala, Yi Cui, Yaroslav Losovyj, and Yongzhu Fu*

A. Bhargav, K. Shashikala, Y. Fu

Department of Mechanical Engineering, Indiana University-Purdue University Indianapolis, Indianapolis, IN 46202, United States

*Corresponding author: yongfu@iupui.edu (Y. Fu)

Y. Cui

Department of Mechanical Engineering, Indiana University-Purdue University Indianapolis, Indianapolis, IN 46202, United States

School of Mechanical Engineering, Purdue University, West Lafayette, IN 47907, United States

Y. Losovyj

Department of Chemistry, Indiana University, Bloomington, IN 47405, United States

Y. Fu

School of Chemistry and Molecular Engineering, Zhengzhou University, Zhengzhou, Henan 450001, China

Y. Ma

Materials Science and Engineering Center, University of Wisconsin-Eau Claire, Eau Claire, WI 54702, United States

Corresponding author: yingma@uwec.edu (Y. Ma) 
Supplementary data:

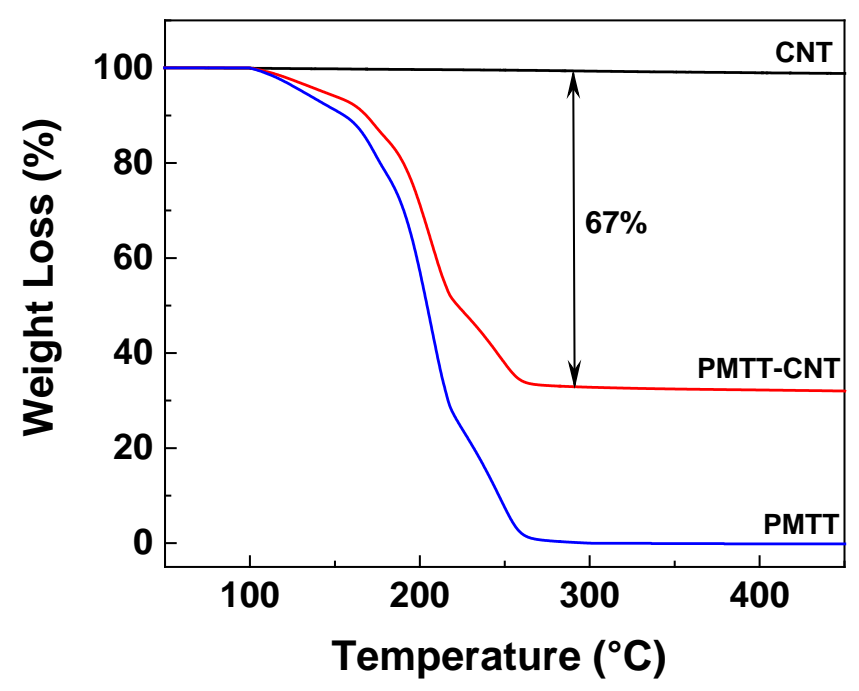

Figure S1. Thermogravimetric analysis (TGA) of a representative batch of PMTT-CNT cathode along with that of pure CNT and PMTT as the baseline showing that $67 \%$ of the cathode consists of PMTT.

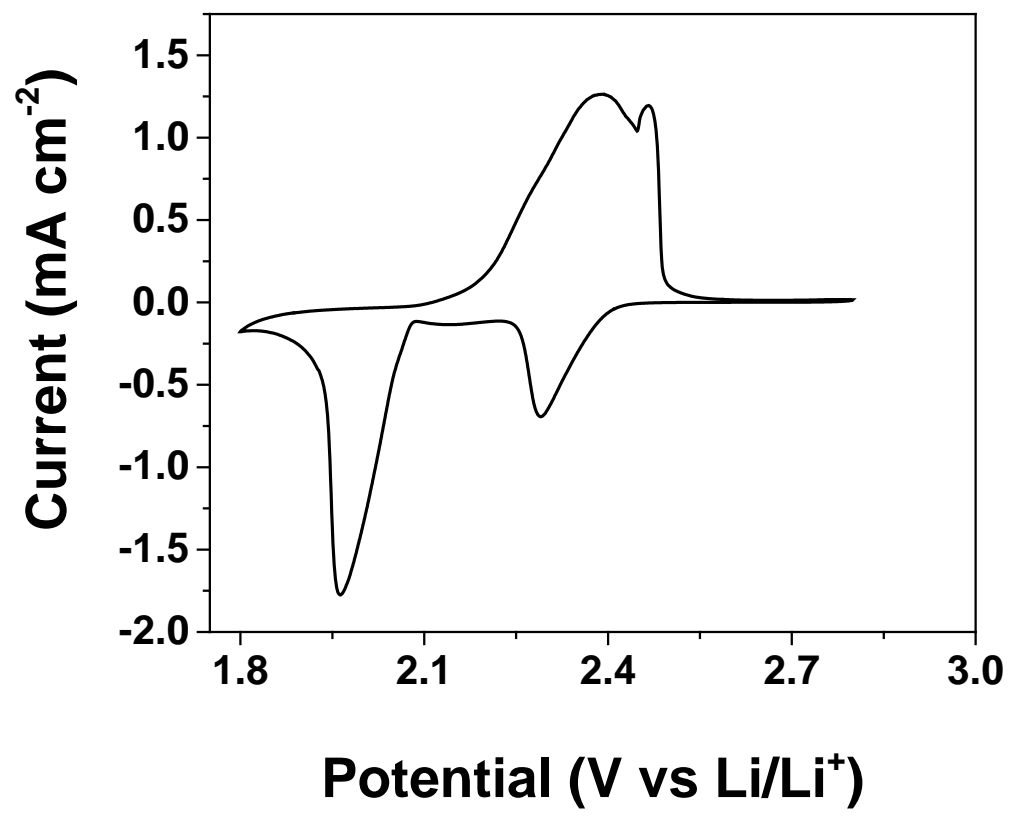


Figure S2. Cyclic voltammogram of sulfur cathode. The potential was swept from open circuit voltage (OCV) to $1.8 \mathrm{~V}$ and then swept back to $2.8 \mathrm{~V}$ at a scanning rate of $0.05 \mathrm{mV} \mathrm{s}^{-1}$.

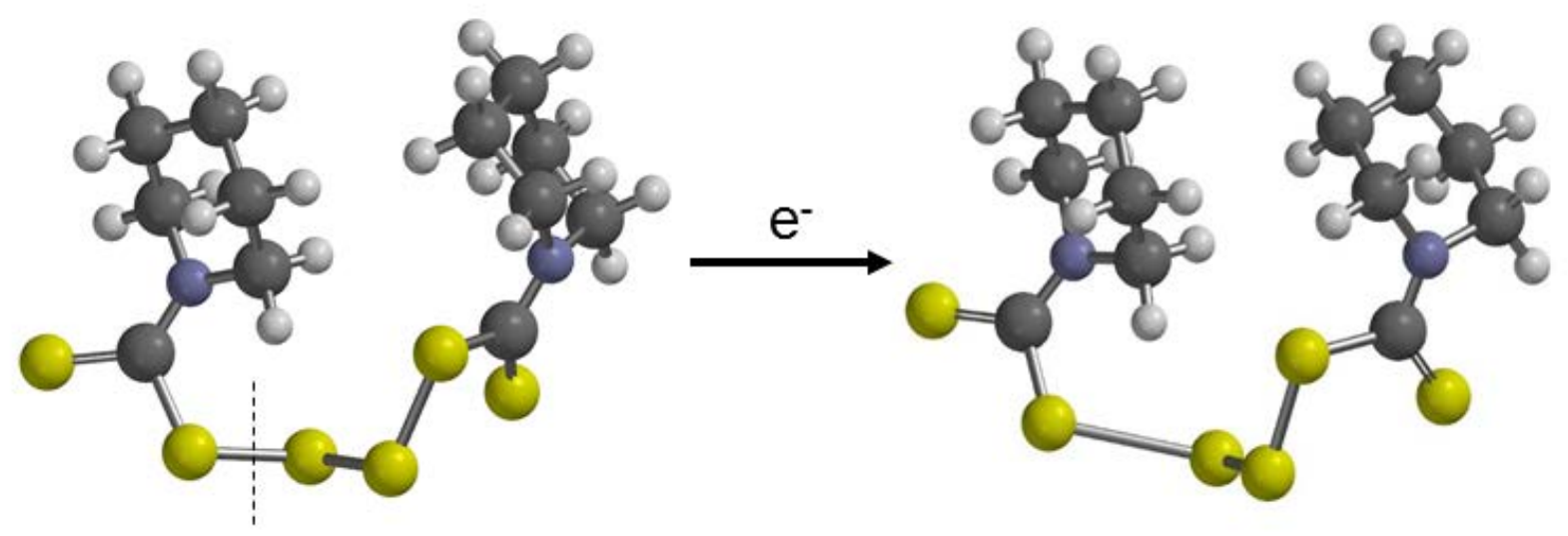

Figure S3. Addition of an electron to PMTT (left) at the S-S bond indicated yields the unstable structure (right).

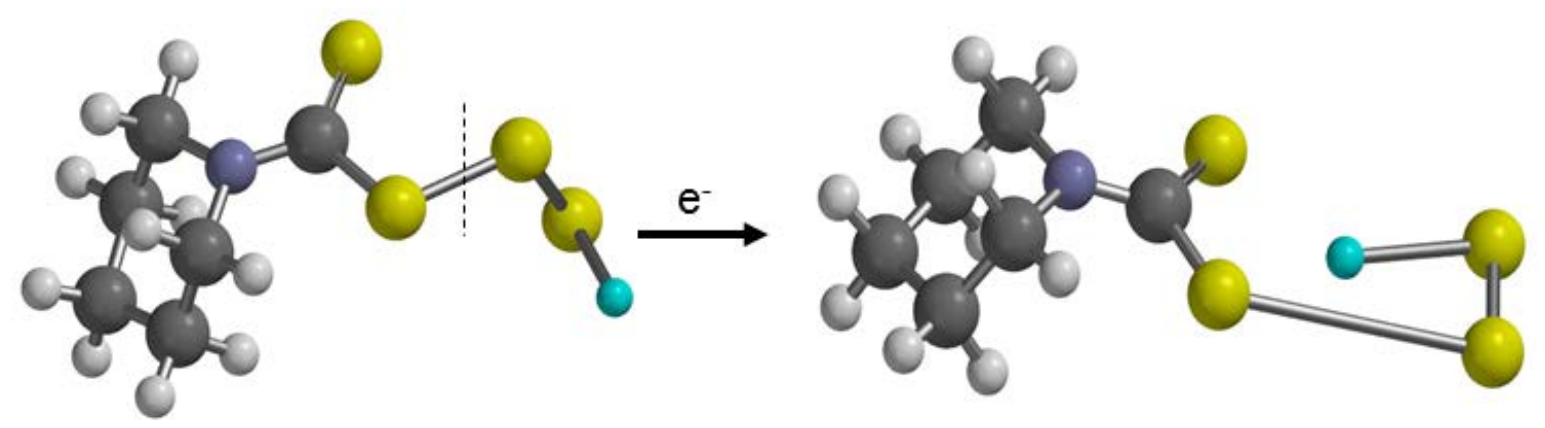

Figure S4. Addition of an electron to intermediate 4 (left) at the S-S bond indicated yields the unstable structure (right). 


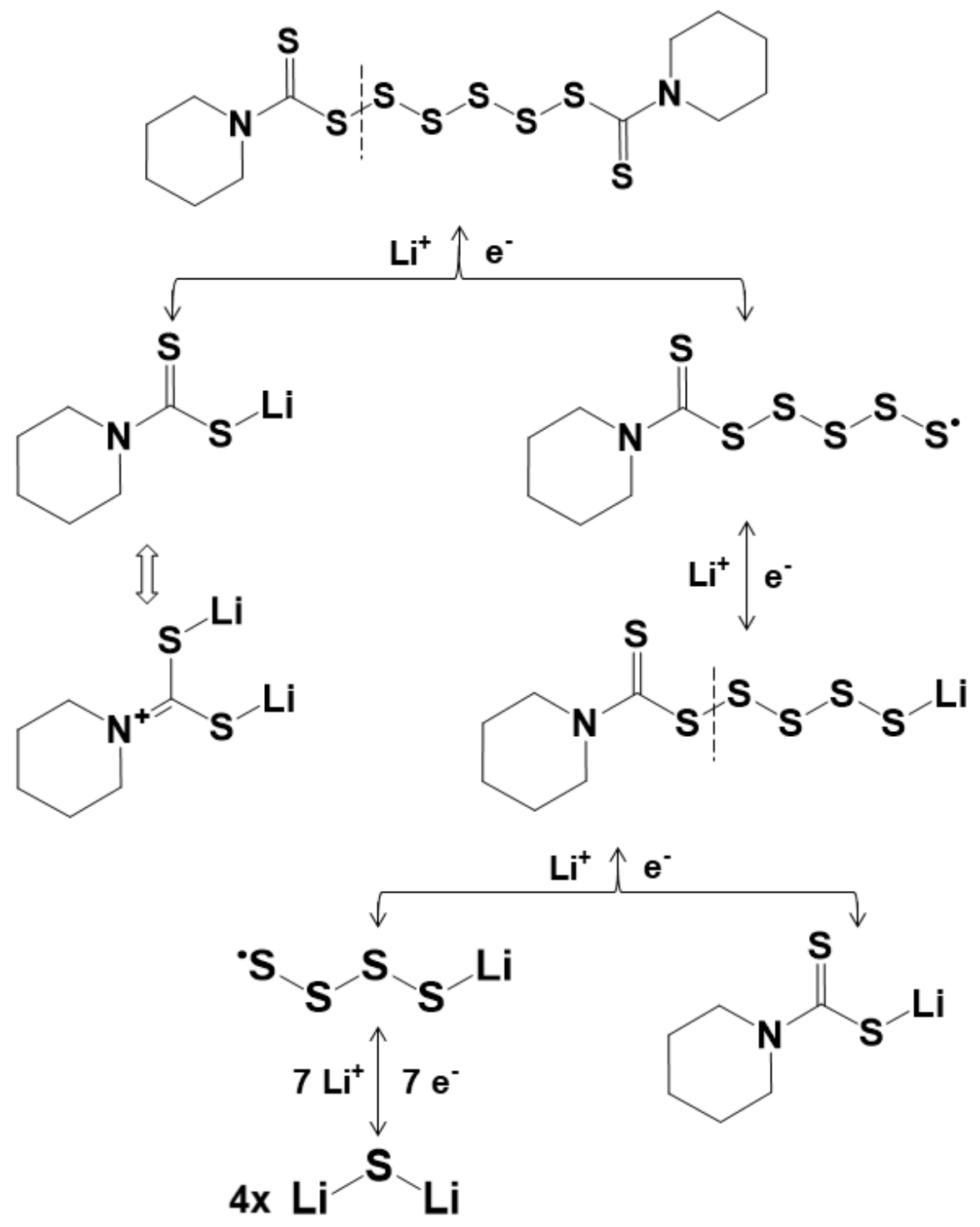

Figure S5. Redox reactions of PMTH during battery cycling. 


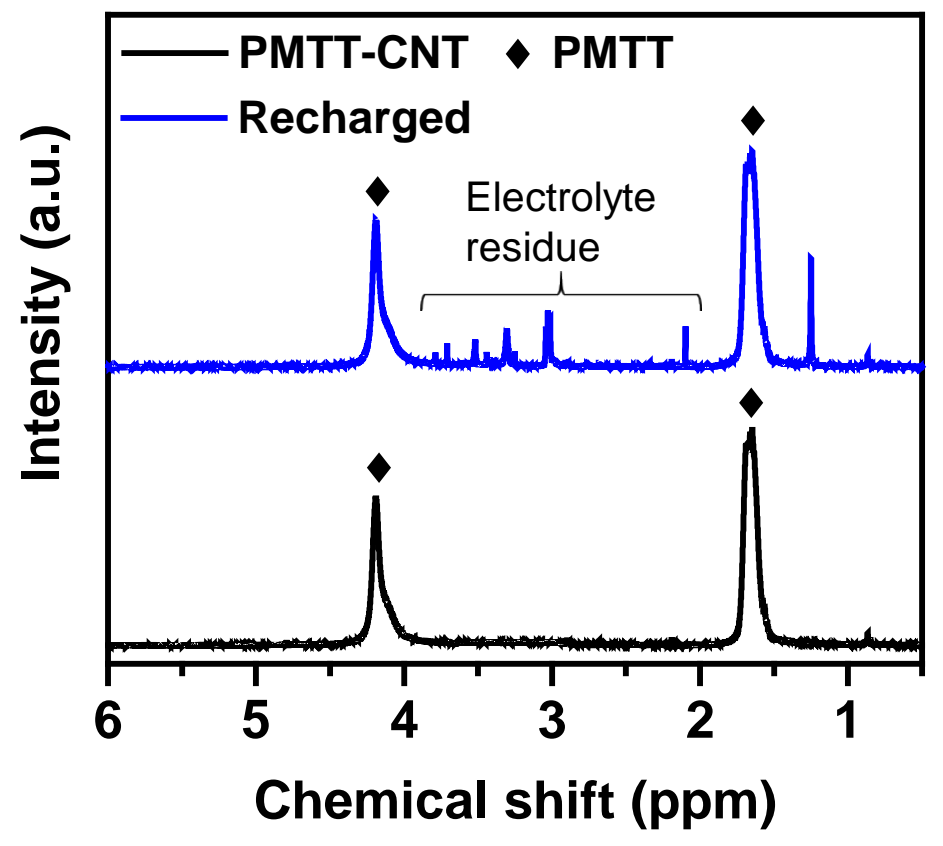

Figure S6. NMR spectrum of fresh PMTT-CNT cathode and after recharge. PMTT peaks were referenced from the Spectral Database for Organic Compounds (SDBS) by the National Institute of Advanced Industrial Science and Technology. (Source: http://sdbs.db.aist.go.jp/sdbs/cgibin/direct_frame_disp.cgi?sdbsno=7145) 

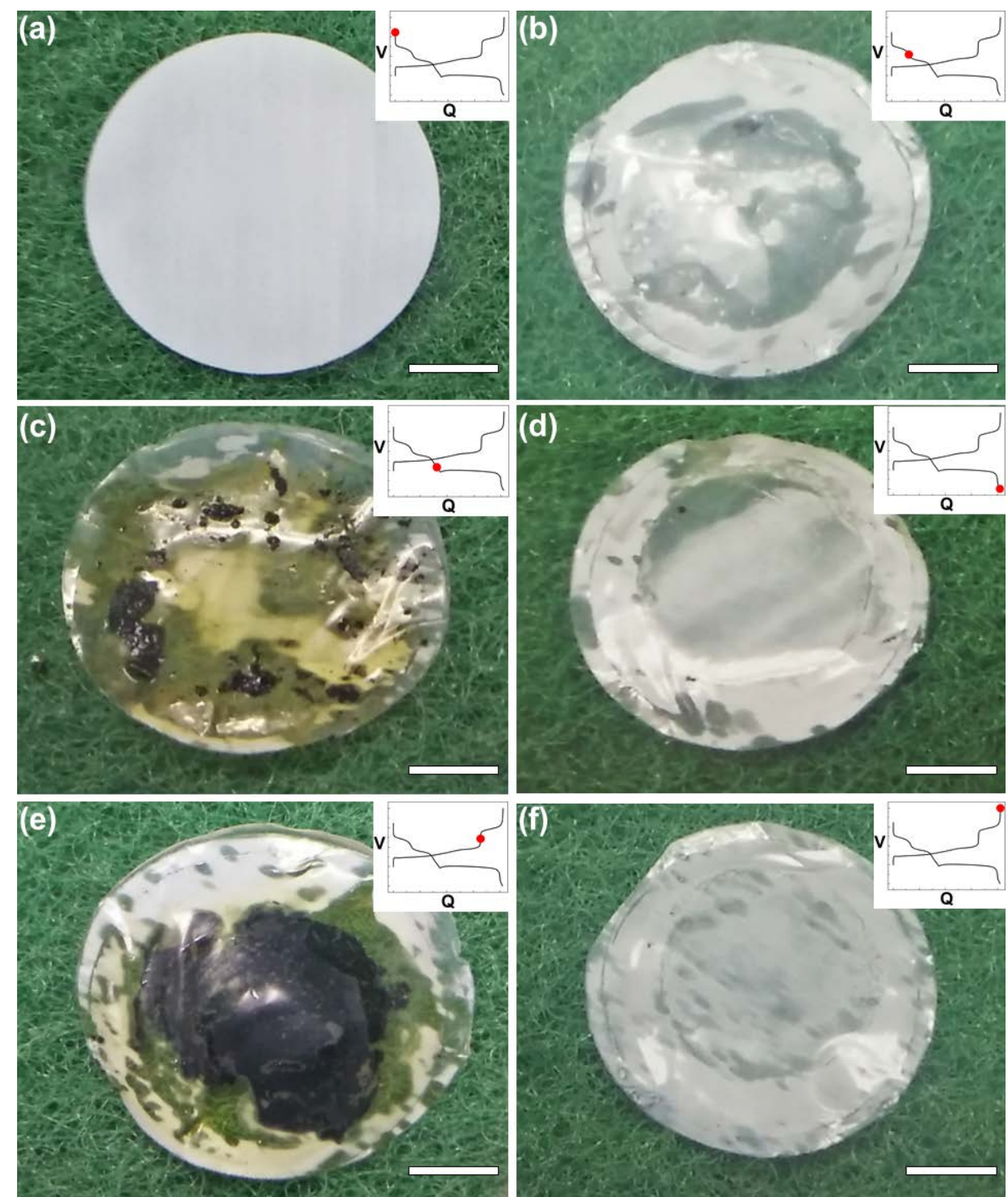

Figure S7. Optical images of the separators taken from the cell at different stages of cycling as represented by the insert figure. All scale bars roughly represent $5 \mathrm{~mm}$. 


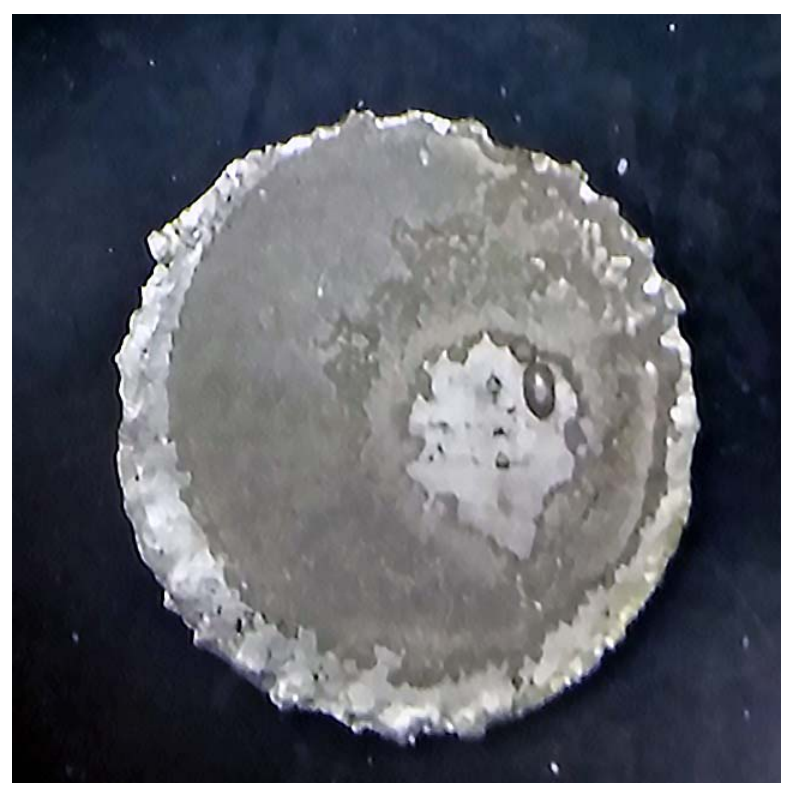

Figure S8. Optical images of the lithium metal anode extracted from the cell containing PMTH cathode after 100 cycles. Mossy and uneven Li deposition including dendrite formation leading to premature cell failure can be visibly observed.

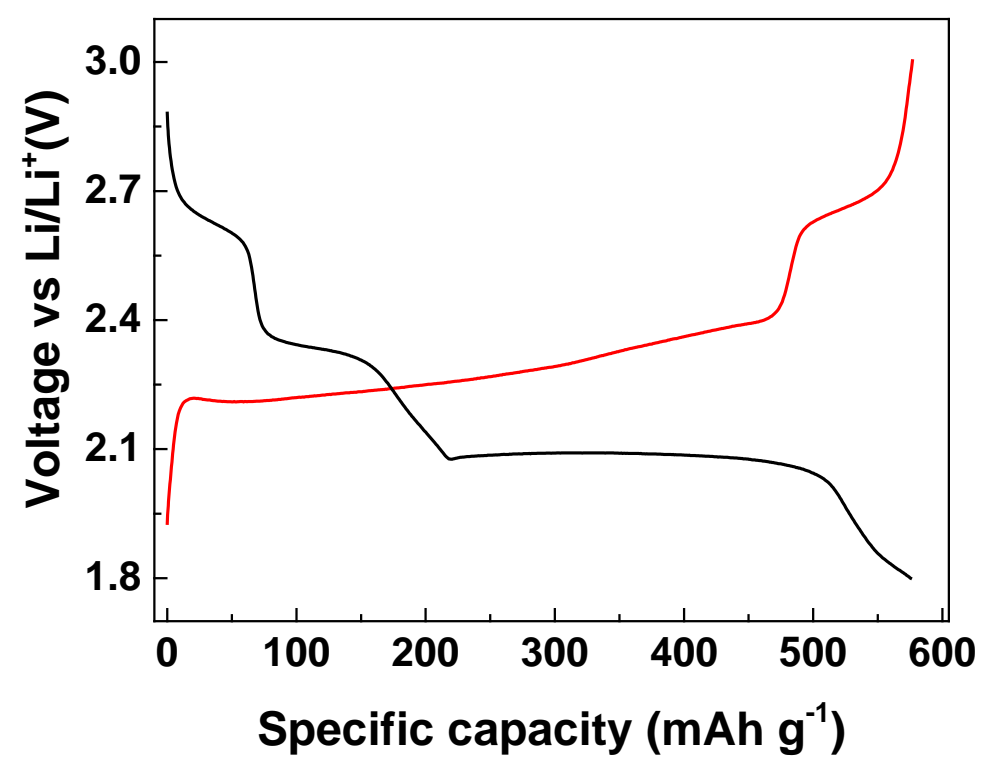

Figure S9. Voltage profile of PMTH-CNT cathode cycled at C/5. The active material (PMTH) loading on the cathode was $6 \mathrm{mg} \mathrm{cm}^{-2}$. The cycling rate was based on PMTH mass in the cathode with 1C $=597$ $\mathrm{mA} \mathrm{g}^{-1}$. 


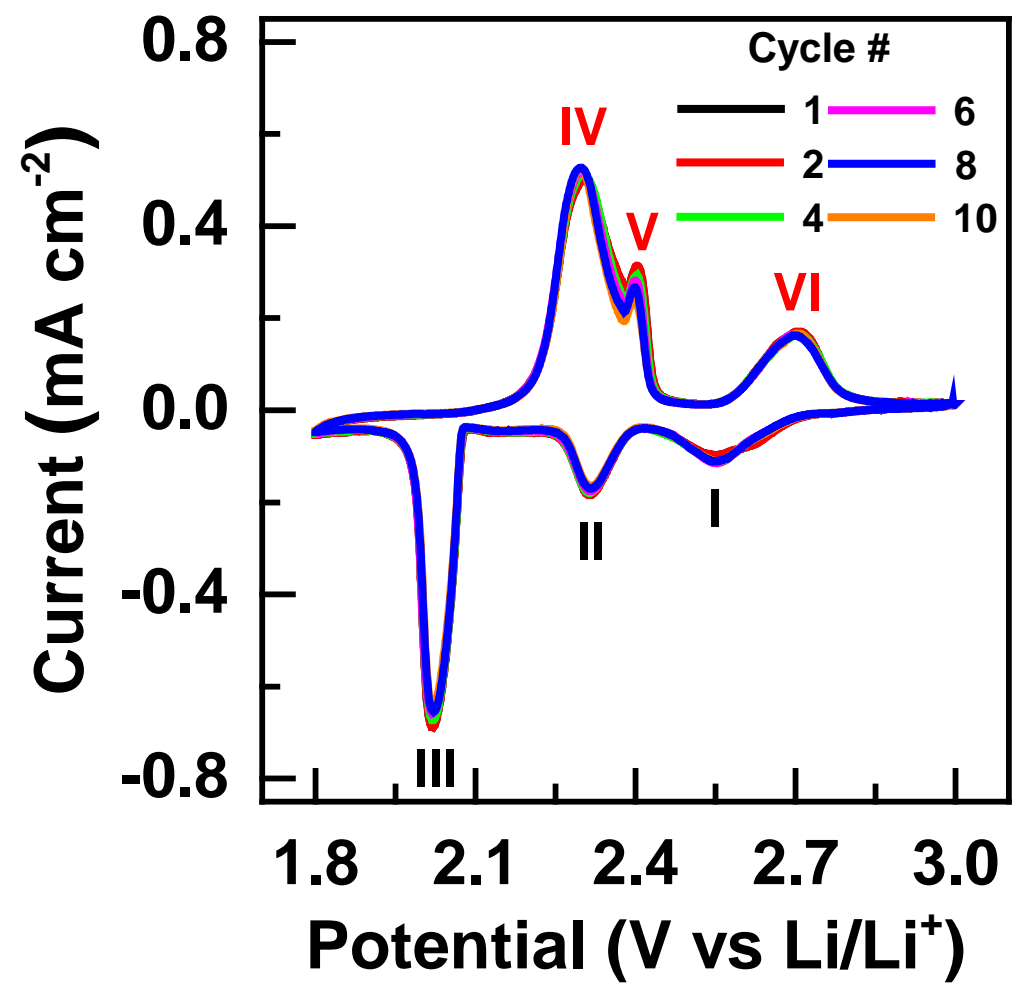

Figure S10. Cyclic voltammogram of PMTH-CNT cathode. The potential was swept from open circuit voltage (OCV) to $1.8 \mathrm{~V}$ and then swept back to $3.0 \mathrm{~V}$ at a scanning rate of $0.05 \mathrm{mV} \mathrm{s}^{-1}$.

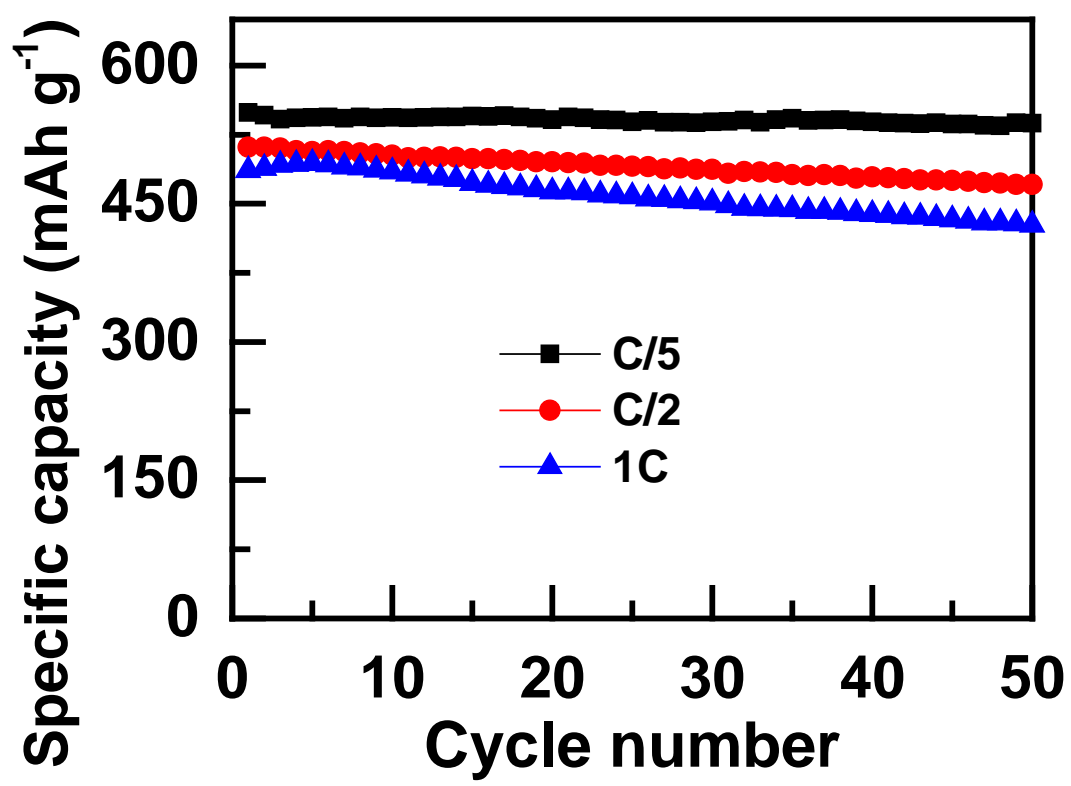

Figure S11. Rate performance of PMTH-CNT cathode. The cycling rate was based on PMTH mass in the cathode with $1 \mathrm{C}=597 \mathrm{~mA} \mathrm{~g}^{-1}$. 


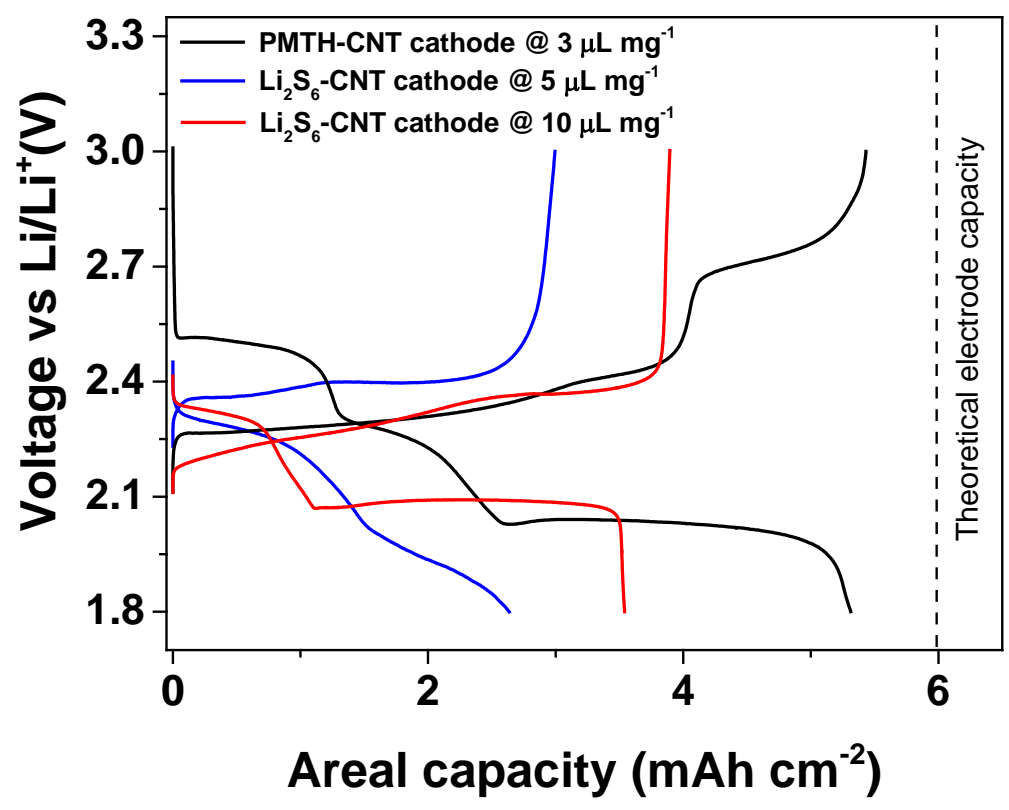

Figure S12. Comparison of performance of high loading PMTH cathode (PMTH loading of $10 \mathrm{mg} \mathrm{cm}^{-2}$ ) with sulfur cathodes at different electrolyte to sulfur ratios. The cells were cycled at the same current density. 